\section{SANDIA REPORT}

SAND98-2276

Unlimited Release

Printed October 1998
MSO619)

Review-and-ApprovatĐesk

FOF-DOE/OSFI, 12690

\title{
Analysis of Multistage and Other Creep \\ Data for Domal Salts \\ NoV $2>1998$ \\ OSTI
}

Darrell E. Munson

Prepared by

Sandia National Laboratories

Albuquerque. New Mexico 87185 and Livermore, California 94550

Sandia is a multiprogram laboratory operated by Sandia Corporation, a Lockheed Martin Company, for the United States Department of Energy under Contract DE-AC04-94AL85000.

Approved for public release; further dissemination unlimited.

\section{Sandia National Laboratories}


Issued by Sandia National Laboratories, operated for the United States Department of Energy by Sandia Corporation.

NOTICE: This report was prepared as an account of work sponsored by an agency of the United States Government. Neither the United States Government nor any agency thereof, nor any of their employees, nor any of their contractors, subcontractors, or their employees, makes any warranty, express or implied, or assumes any legal liability or responsibility for the accuracy, completeness, or usefulness of any information, apparatus, product, or process disclosed, or represents that its use would not infringe privately owned rights. Reference herein to any specific commercial product, process, or service by trade name, trademark, manufacturer, or otherwise, does not necessarily constitute or imply its endorsement, recommendation, or favoring by the United States Government, any agency thereof, or any of their contractors or subcontractors. The views and opinions expressed herein do not necessarily state or reflect those of the United States Government, any agency thereof, or any of their contractors.

Printed in the United States of America. This report has been reproduced directly from the best available copy.

Available to DOE and DOE contractors from

Office of Scientific and Technical Information

P.O. Box 62

Oak Ridge, TN 37831

Prices available from (615) 576-8401, FTS 626-8401

Available to the public from

National Technical Information Service

U.S. Department of Commerce

5285 Port Royal Rd

Springfield, VA 22161

NTIS price codes

Printed copy: A04

Microfiche copy: A01

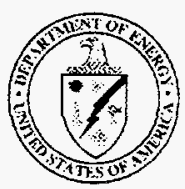




\section{CIISCLAIMER}

Portions of this document may be illegible electronic image products. Images are produced from the best available original document. 
SAND98-2276

Unlimited Release

Printed October 1998

\title{
ANALYSIS OF MULTISTAGE AND OTHER CREEP DATA FOR DOMAL SALTS
}

\author{
Darrell E. Munson \\ Underground Storage Technology Department \\ Sandia National Laboratories \\ P.O. Box 5800 \\ Albuquerque, NM 87185-0706
}

\begin{abstract}
There have existed for some time relatively sparse creep databases for a number of domal salts. Although all of these data were analyzed at the time they were reported, to date there has not been a comprehensive, overall evaluation within the same analysis framework. Such an evaluation may prove of value. The analysis methodology is based on the Multimechanism Deformation (M-D) description of salt creep and the corresponding model parameters determined from conventional creep tests. The constitutive model of creep was formulated through application of principles involved in micromechanical modeling. It was possible, at minimum, to obtain the steady state parameters of the creep model from the data on the domal salts. When this was done, the creep of the domal salts, as compared to the well-defined Waste Isolation Pilot Plant (WIPP) bedded clean salt, was either essentially identical to, or significantly harder (more creep resistant) than WIPP salt. Interestingly, the domal salts form two distinct groups, either soft or hard, where the difference is roughly a factor of ten in creep rate between the two groups. As might be expected, this classification corresponds quite well to the differences in magnitude of effective creep volume losses of the Strategic Petroleum Reserve (SPR) caverns as determined by the CAVEMAN cavern pressure history analysis, depending upon the specific dome or region within the dome. Creep response should also correlate to interior cavern conditions that produce salt falls. While, in general, the caverns in hard salt have a noticeably greater propensity for salt falls, a smaller number of similar events are exhibited even in the caverns in soft salt.
\end{abstract}




\section{Acknowledgments}

The author would like to acknowledge the continued support of Bob Myers, DOE SPR/PMO who initiated the study of hanging string damage and the behavior of cavern salt materials. Also, the support of Jim Linn, who leads the SPR program at Sandia National Laboratories, is highly valued. Reviews by Arlo Fossum and Nancy Brodsky were greatly appreciated, as were the remarks by Brian Ehgartner. 


\section{Contents}

Abstract............................................................................... 3

Acknowledgments............................................................................ 4

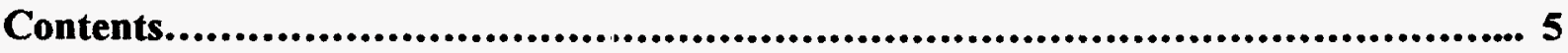

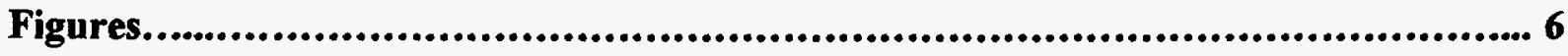

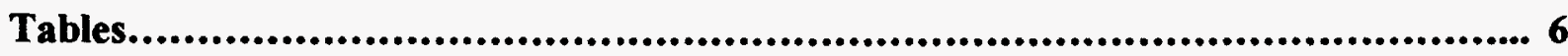

1.0 Introduction........................................................................ 7

2.0 Creep Testing.......................................................................... 9

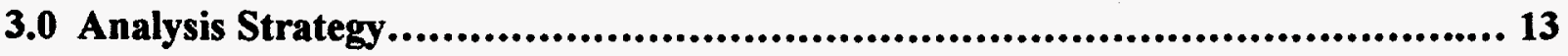

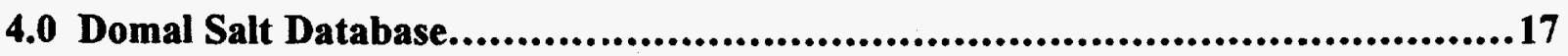

5.0 Analysis of Creep Data..............................................................23

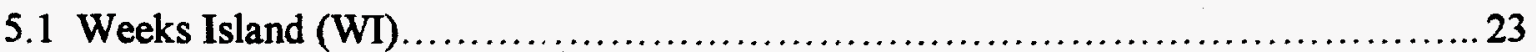

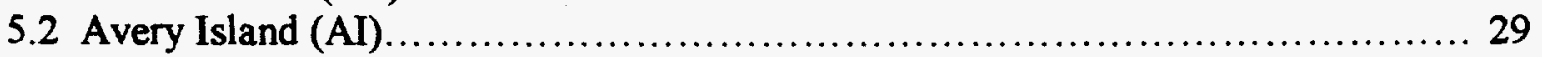

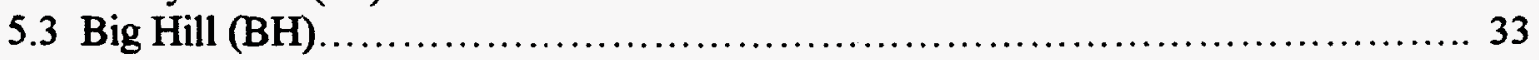

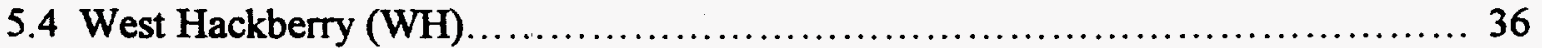

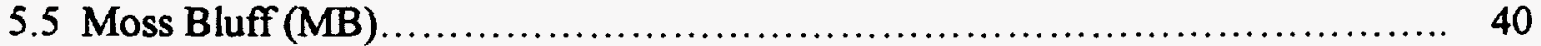

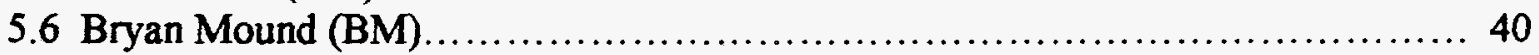

5.7 Bayou Choctaw (BC) ..................................................... 49

5.8 Jennings Dome (JD) .......................................................... 49

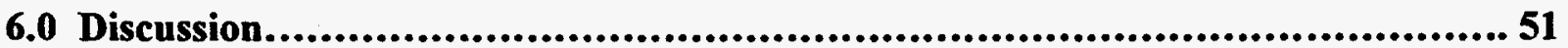

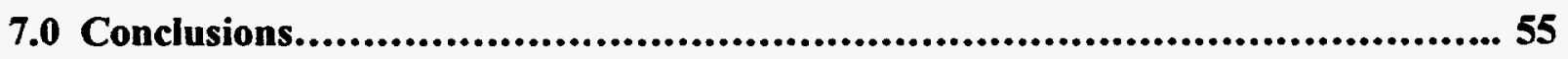

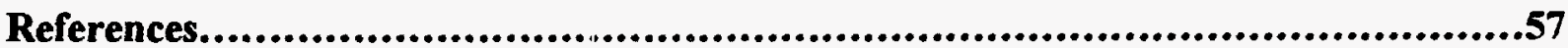

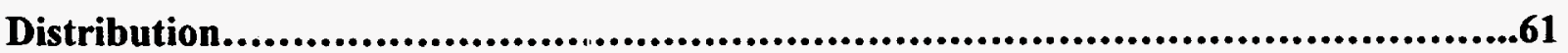




\section{Figures}

Figure 1. Raw Creep Data for a Weeks Island Specimen [Mellegard and Pfeifle, 1996] ... 10

Figure 2. Axial Strain Rate Asymptote to Steady State [Mellegard and Pfeifle, 1996]..... 11

Figure 3. Transient Creep Curves for Various Applied Stresses

[Munson and Dawson, 1982].

Figure 4. Steady State Response of Weeks Island and WIPP Salt

[Munson and Ehgartner, 1997].

Figure 5. Transient Strain Limit for Weeks Island and WIPP Salt

[Munson and Ehgartner, 1997].

Figure 6. Workhardening Response of Weeks Island and WIPP Salt

[Munson and Ehgartner, 1997].................................... 28

Figure 7. Steady State Response of Avery Island Domal Salt [Data of DeVries, 1988] ..... 32

Figure 8. Transient Strain Limit of Avery Island Domal Salt [Data of DeVries, 1988]..... 34

Figure 9. Delta Values of Avery Island Domal Salt [Data of DeVries, 1988] .............. 35

Figure 10. Steady State Creep Rates of Big Hill Domal Salt [Data of Wawersik, 1985].... 37

Figure 11. Conventional Test Steady State Creep Rates for West Hackberry

[Data of Wawersik, et al., 1980b]...

Figure 12. Incremental Test Creep Rates for West Hackberry

[Data of Wawersik and Zeuch, 1984]

Figure 13. Incremental Test Creep Rates for West Hackberry, Stress Drops Removed

[Data of Wawersik and Zeuch, 1984].

Figure 14. Incremental Test Creep Rates for Moss Bluff [Data of Wawersik, 1992] ........ 42

Figure 15. Conventional Test Steady State Creep Rates for Bryan Mound

[Data of Wawersik, et al, 1980a].

Figure 16. Incremental Test Creep Rates for Bryan Mound

[Data of Wawersik and Zeuch, 1984]

Figure 17. Incremental Test Creep Rates for Bryan Mound

[Data of Wawersik and Zeuch, 1984]

Figure 18. Incremental Test Creep Rates for Bayou Choctaw

[Data of Wawersik and Zeuch, 1984].

Figure 19. Incremental Test Creep Rates for Jennings Dome

[Data of Wawersik and Zimmerer, 1994]

Figure 20. Caveman Calculated Volume Creep Rates for SPR Caverns [Linn, 1997]. 54

\section{Tables}

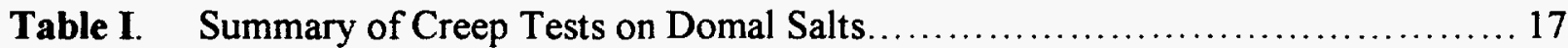

Table II. Creep Data from Tests on Domal Salts...................................... 18

Table III. Avery Island Creep Database [DeVries, 1988] ............................ 30

Table IV. Structure Factor Multiplication Factor from WIPP $25^{\circ} \mathrm{C}$ Pure Salt Baseline..... 51

Table V. Suggested Parameter Values for the M-D Model. 


\subsection{INTRODUCTION}

Although it has been some time since the initial creep tests of the domal salts of the Strategic Petroleum Reserve (SPR) storage sites were reported and analyzed by the initial investigators, there has been no subsequent comprehensive, overall analysis of the collective database, as yet. It seems that some attempt to do such a comprehensive evaluation is warranted. For this evaluation, it is necessary to apply a fundamental analysis framework uniformly to the databases. As a result, we will analyze these data in terms of the methods developed for the Waste Isolation Pilot Plant (WIPF) Program [Munson, et al., 1989]. The WIPP analysis determines parameters based on data from standard creep tests. In general, these methods have been applied to determine parameter sets for the salt materials obtained from bedded salt layers of the WIPP facility. When combined with the appropriately framed constitutive model and numerical codes, results of this analysis method have provided parameter sets that were successful in predicting underground salt mine structural response [Munson, 1997].

The SPR sites are located in the Wreks Island, Bayou Choctaw, and West Hackberry domes in Louisiana and the Bryan Mound and Big Hill domes in Texas. In the late 1970's and early 1980 's, a relatively small number of core samples became available from the SPR sites either from core drilling of the solutioning wells or from special purpose boreholes. Specimens prepared from these cores were tested according to acceptable creep testing methods of that time. Often, this involved multistage testing methods with numerous changes of stress and temperature during the creep deformation of an individual specimen. Even though multistage tests differ significantly from standard creep tests, most of these multistage creep-testing methods are not incompatible with the WIPP standard creep testing methods and we can still develop some necessary information on creep parameters from these tests. Early creep tests were performed by Wawersik, et al. [1980a] on material from the Bryan Mound site and by Wawersik, et al. [1980b] on material from the West Hackberry site. Later, Wawersik and Zeuch [1984] performed multistage tests on specimens from Bryan Mound, West Hackberry, and Bayou Choctaw domes. Recently, using conventional test procedures compatible with the WIPP creep methodology, creep tests were performed on specimens obtained from borehole cores of the Weeks Island salt dome [Mellegard and Pfeifle, 1996], which contains an underground mine used for SPR storage. Creep results have been reported for domal salts from other sites as well, specifically from the Avery Island [DeVries, 1988], Moss Bluff [Wawersik, 1992] and Jennings [Wawersik and Zimmerer, 1994] domes. Although these results in their entirety form a significant database, they are not necessarily sufficient for a complete parameter evaluation according to the WIPP analysis methodology. Nevertheless, various degrees of partial parameter evaluations are possible.

In preparing for the analysis of the creep data, it is necessary to have a detailed understanding of the influence of various testing methods used for creep studies. These testing methods are presented first. Then, the analysis itself requires a theoretical framework or model of material response that permits all of the data to be placed in the proper context and that provides rules for the analysis. In this context, all of the available data are presented for each individual dome material and then analyzed according to the established rules. Partial parameter sets for each individual dome material are determined from the data and from comparisons with the complete parameter set from the WIPP clean salt database. From these comparisons, two 
different salt creep responses are evident. One group of domal salts has a steady state creep behavior essentially the same as WIPP clean salt, while the other group of domal salts creep much slower than the WIPP salt. This difference between domal salt response has been suggested previously because of the low steady-state creep rates of Bryan Mound salt [Wawersik, et al., 1980a] compared to other domal salts, but the effect was not quantified to the extent possible here. The results of the analyses are compared to the volume creep rate of the SPR caverns as measured by the CAVEMAN analysis [Ehgartner, et al., 1995] of the historical pressurization data. This comparison suggests the steady state creep rate and the volume creep response are correlated. Attempts to correlate the steady state creep response of the cavern material to the potential for salt falls is not so straightforward, even though the hard salt caverns clearly have a greater number of salt fall events. The presentation concludes with a summary of the analysis results. 


\subsection{CREEP TESTING}

Before analyzing the individual creep results, it is necessary to understand the different types of creep testing and how the testing methodology affects the test results. Regardless of the testing methodology, we will use at uniform approach to analyze all of the test data. This approach stems from the fundamental concept of creep as controlled by micromechanical mechanisms, especially the three dominant mechanisms in the temperature and stress regimes relevant to the available creep data. These mechanisms were defined through a deformation mechanism map [Munson, 1979]. In addition, the analysis specifically follows dictates of the Multimechanism Deformation (M-D) creep model developed by Munson and Dawson [1984]. This model utilizes the techniques and data of standard or conventional creep tests for parameter evaluation [Munson, et al., 1989].

The standard creep test is one in which the specimen strain is measured as a function of time for imposed conditions of constant uniaxial stress and constant temperature. For geotechnical applications, the uniaxial stress is typically replaced by a triaxial compression stress condition, which suppresses fracture in geomaterials and more accurately duplicates the natural conditions around underground openings. These standard creep tests produce most directly the transient and steady state response of the material being tested. However, standard creep tests are time consuming and costly. This has led some investigators to utilize "staged" tests in an attempt to increase data retrieval from a single specimen. (Henceforth, we use "incremental" rather than "staged" as the descriptive terminology for these tests to avoid confusion with historical descriptions of the three stages of creep behavior). Various specialized creep tests have been developed. Normally for geologic materials, such tests are triaxial compression tests in which either the stress or temperature, or both, are changed periodically in a step-wise fashion to give small time increments of creep at constant stress and temperature, all upon the same specimen. Using the concept of a transient creep curve [Munson and Dawson, 1982], the consequences of these incremental stress and temperature changes can be examined.

Data from a standard creep test is shown in Figure 1. From raw creep results such as these it is relatively easy to misinterpret the relevant behavior. However, if the derivative of the strain with respect to time (instantaneous strain rate) is determined and then plotted against time, the curve of Figure 2 is produced. The figure indicates that the strain rate diminishes with time, and eventually asymptotes to a steady state (constant) rate. Although there can still be some uncertainty in determining the exact asymptote in Figure 2, the resulting achievement of steady state is clearly more apparent than from the raw data curve. However, in order to understand the creep curve in greater detail, it is necessary to further reframe the plot of Figure 2. This is accomplished by visualizing the creep strain as essentially involving two components, one produced by a steady state creep rate and one produced by a transient creep rate. We can effectively separate these strains by using the steady state rate to normalize the instantaneous strain rate and by introducing an internal state parameter which is a measure of the transient strain. In contrast to the creep strain, which increases monotonically, the internal state parameter may either increase or decrease in transient creep, but remains constant in steady state creep. This plot of the normalized instantaneous strain rate against the internal state parameter provides a significant insight into creep, especially when the plot includes both workhardening and recovery processes. This curve, as shown in Figure 3, is called the 
"transient creep curve." Actually, a family of transient creep curves for various constant applied stresses are shown in Figure 3 [Munson and Dawson, 1982]. At any given applied stress, for example $\sigma_{1}$, the strain rate of an initially undeformed specimen decreases with time,

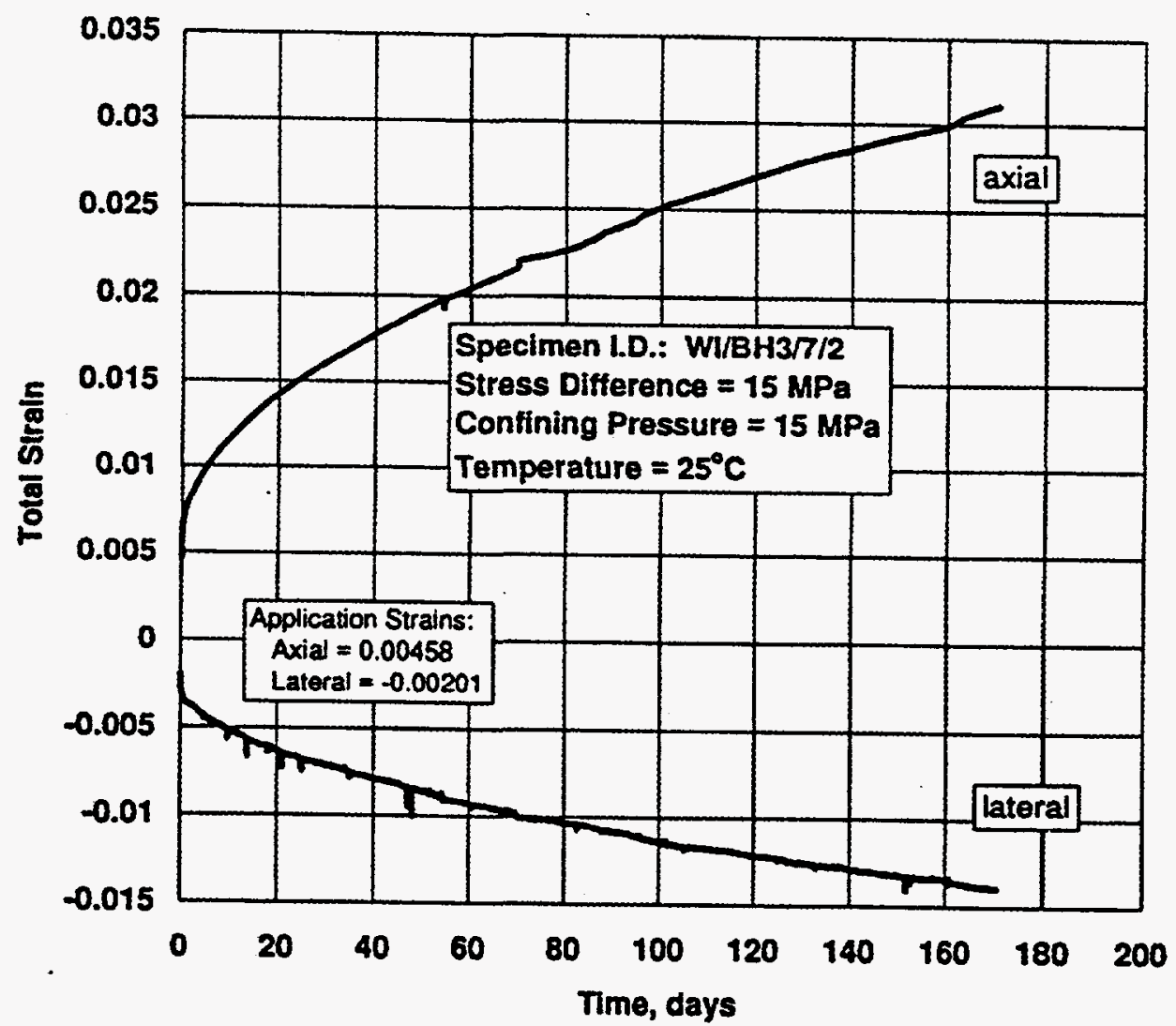

Figure 1. Raw Creep Data for a Weeks Island Specimen [Mellegard and Pfeifle, 1996].

or with an increase in the internal state parameter, $\zeta$, until the strain rate becomes the equilibrium or steady state strain rate. At this point, shown on the $\sigma_{1}$ transient strain curve, the strain rate and internal state parameter will remain constant. However, for a specimen that is initially workhardened, the current state parameter value may be greater than the state parameter value at steady state, i.e., to the right of the steady state point on the $\sigma_{1}$ transient strain curve. With time, the state parameter of this specimen will decrease, and although the specimen strain continues to increase, the state of the material will move backward up the transient curve, to eventually attain the steady state condition. Then the strain rate will again become constant.

Transient strain curves were initially proposed by Munson and Dawson [1982] as a strategy to treat transient creep during stress and temperature changes. A hypothetical series of stress increases and stress decreases such as might be generated in an incremental test are illustrated 
in Figure 3. The strain rate history for each increment can be deduced from the figure. While, in theory, such changes can give information about the magnitude of the stress exponent and

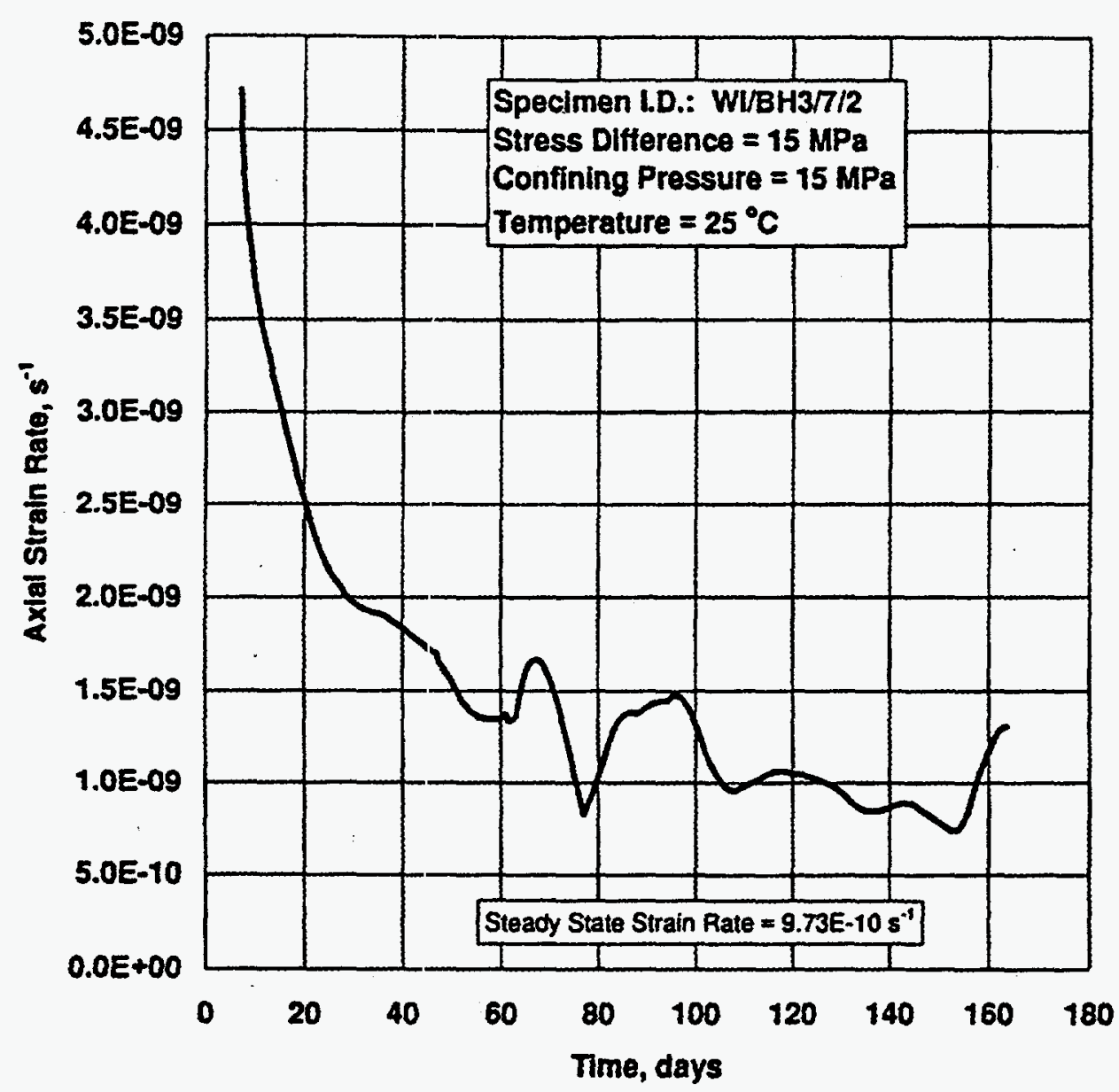

Figure 2. Axial Strain Rate Asymptote to Steady State [Mellegard and Pfeifle, 1996].

the activation energy, they do not necessarily give the essential information about the steady state creep condition as a function of stress and temperature. Creep rates are reported at the beginning and end of each stress or temperature increment. Except for special conditions, these ending rates are not the steady state rates. Moreover, the ending rates are not unique. (This could be demonstrated on the figure through construction of another hypothetical series of stress increases where the endirg rates either decrease or increase, depending upon the exact stress-time conditions). Because the sequence and direction of stress and temperature increments are essentially random, many different scenarios are possible based on the actual tests.

As a hypothetical example of an incremental test, the sequence of stress changes shown in Figure 3 can be used to illustrate the specimen response adequately. The specimen is initially loaded under $\sigma_{1}$. After some interval of decreasing transient strain rate, the stress is increased 


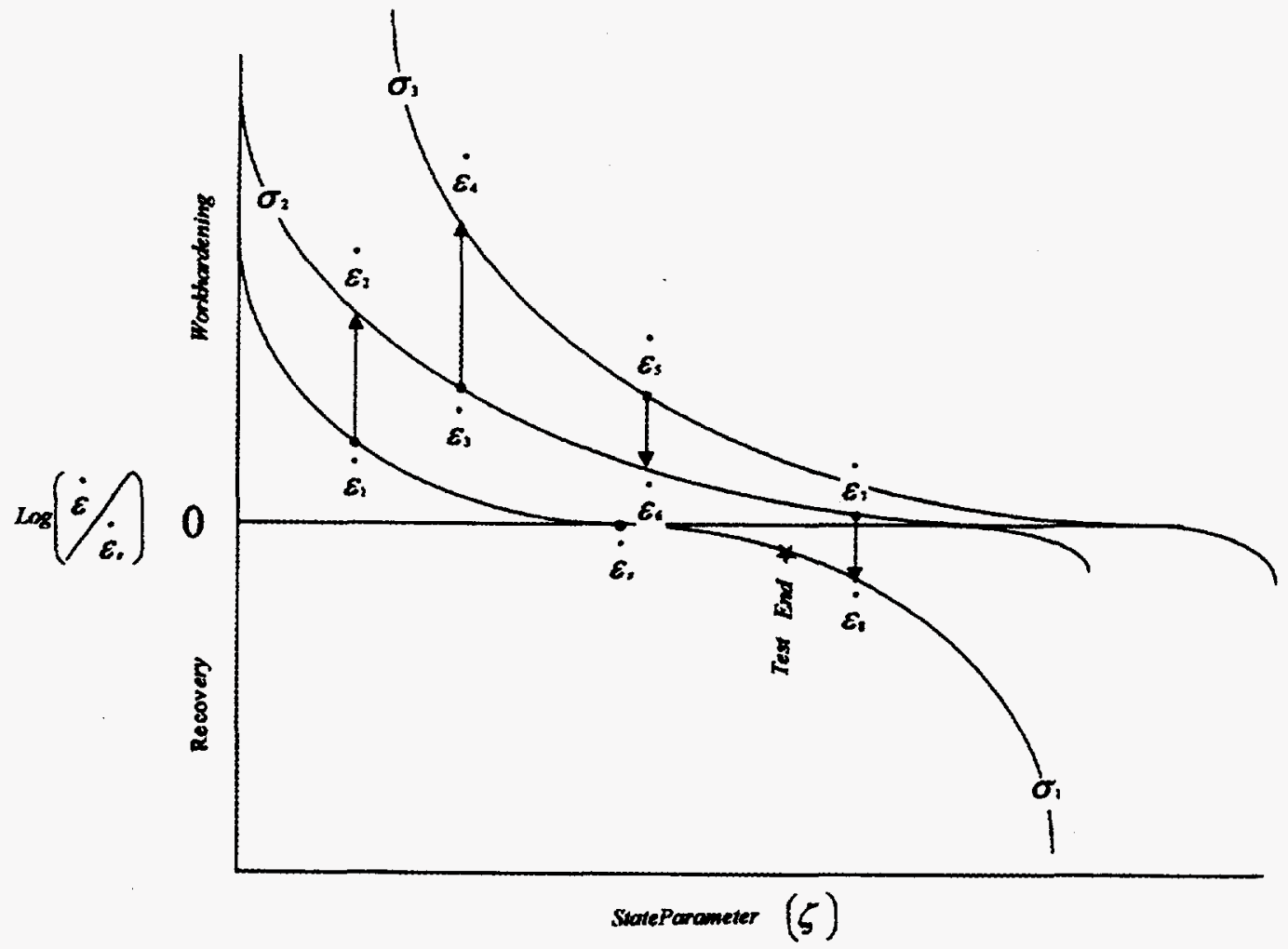

Figure 3. Transient Creep Curves for Various Applied Stresses [Munson and Dawson, 1982].

to $\sigma_{2}$, with the subsequent abrupt increase in strain rate followed by a decreasing transient strain rate. After an interval of time, the stress is further raised to $\sigma_{3}$. Note that the strain rates at each higher stress level still diminish with time, as one would expect, but they never become steady state rates. From $\sigma_{3}$, the stress is lowered to $\sigma_{2}$, and while the rate decreases, it is still not in steady state by the time the stress is again further reduced to $\sigma_{1}$. However, this last stress decrease causes an unusually strong decrease in strain rate since the specimen internal state is now on a recovery branch. This occurs because the workhardening and recovery branches of the transient curve are of opposite curvature. The test ends, in this case, still on the recovery branch, with a strain rate less than the steady state creep rate. If we use the final strain rate reported for each of the increments, exactly as was done for some staged salt tests, then we will have four rates above the steady state rate and one below the steady state rate. None of these rates, however, will be the actual steady state rate, although one will be close. The crucial problem with the analysis of these kinds of incremental test data is that we do not know the steady state rate, and therefore never quite know quantitatively how the reported rates are related to steady state.

In all of the following discussion of the analysis, as well as the actual analysis of the creep data, we want to keep the details of Figure 3 in our minds. This illustration is the clearest possible method of keeping track of the complex series of events during any incremental creep test. The figure represents not only the form of the experimental results of transient creep but, as we shall see, also the form of the mathematical description of creep. 


\subsection{ANALYSIS STRATEGY}

In addition to the empirical observations, as described above, it is equally possible, and perhaps more important, to make use of what is known about the general behavior of salt with respect to achieving the steady state condition in order to formulate an analysis strategy. We will make extensive use our knowledge of the constitutive description of the creep response of salt in the following discussions. "We will also use the well-documented, standard creep test results that define the steady state creep response for a WIPP "clean" salt $(99.5+\% \mathrm{NaCl})$ [Munson, et al., 1989] as a baseline for judging the relative creep behavior of the domal salts.

Principles gained from our understanding of the constitutive behavior of WIPP salt will form the principal basis for the analysis strategy. Not only do the constitutive equations of the M-D model define the necessary material parameters, but also they permit the formulation of rules of the analysis. In developing the constitutive description, we concern ourselves only with the temperature and stress range encountered in mining and storage cavern operations, typically low temperature and low to moderately high stresses. For these conditions, the creep is envisioned as arising from the contributions of three appropriate micromechanical mechanisms as determined from the deformation mechanism-map [Munson, 1979]. These mechanisms are (1) a dislocation climb controlled creep mechanism at high temperatures and low stresses, (2) an empirically specified but undefined mechanism at low temperatures and low stresses, and (3) a dislocation slip controlled mechanism at high stresses [Munson, et al., 1989]. These mechanisms act in parallel, which means the individual steady state creep rates can be summed over the three mechanisms to give the total steady state creep rate, as follows:

$$
\dot{\varepsilon}_{S}=\sum_{i=1}^{3} \dot{\varepsilon}_{S_{i}}
$$

The steady state creep rates for the individual mechanisms, respectively, are given by:

$$
\begin{aligned}
& \dot{\varepsilon}_{s_{1}}=A_{1} e^{\frac{-Q_{1}}{R T}}\left(\frac{\sigma}{\mu(1-\omega)}\right)^{n_{1}} \\
& \dot{\varepsilon}_{S_{2}}=A_{2} e^{\frac{-Q_{2}}{R T}}\left(\frac{\sigma}{\mu(1-\omega)}\right)^{n_{2}} \\
& \dot{\varepsilon}_{s_{3}}=\left|H \sigma-\sigma_{0}\right|\left(B_{1} e^{\frac{-Q_{1}}{R T}}+B_{2} e^{\frac{-Q_{2}}{R T}}\right) \sinh \left[\frac{q\left(\frac{\sigma}{1-\omega}-\sigma_{0}\right)}{\mu}\right]
\end{aligned}
$$

where the numerical subscripts refer to the appropriate mechanism, the A's and B's are structure factors, $Q$ 's are activation energies, $R$ is the universal gas constant, $T$ is the absolute temperature, $\mu$ is the shear modulus, $q$ is the stress constant, $\sigma_{0}$ is a stress limit, and $H$ is a 
Heaviside step function with argument $\left(\sigma-\sigma_{0}\right)$. It has been shown [Munson, et al., 1989] through multiaxial experiments that the proper equivalent stress measure is $\sigma=\left|\sigma_{1}-\sigma_{3}\right|$.

The equivalent total strain rate is treated through a multiplier on the steady state rate, as

$$
\dot{\varepsilon}_{e q}=F \dot{\varepsilon}_{s}
$$

where the multiplier involves three branches of the transient creep curve: workhardening, steady state, and recovery, respectively, as follows:

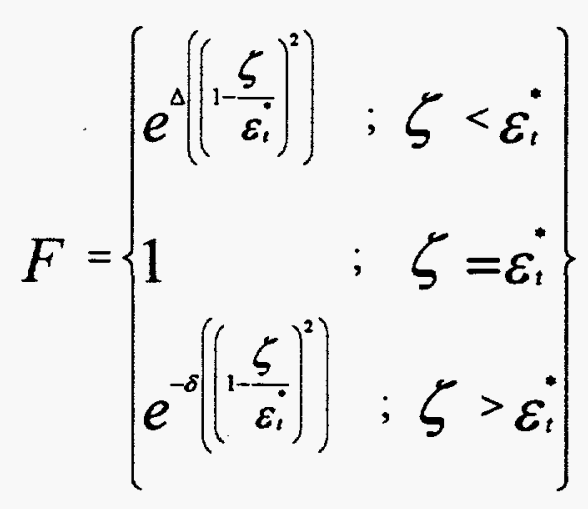

Here, $\Delta$ is the workhardening parameter, $\delta$ is the recovery parameter, $\zeta$ is the state parameter, and $\varepsilon^{*}{ }_{t}$ is the transient strain limit. The state parameter rate is given by

$$
\dot{\zeta}=(F-1)_{\mathcal{E}_{s}}
$$

The transient strain limit is defined by

$$
\dot{\varepsilon_{t}}=K_{0} e^{c T}\left(\frac{\sigma}{\mu(1-\omega)}\right)^{m}
$$

where $\mathrm{K}_{0}$ and $\mathrm{c}$ are constants and $\mathrm{m}$ is a material constant.

The workhardening, $\Delta$, and recovery, $\delta$, parameters are described through linear functions, as follows:

$$
\begin{gathered}
\Delta=\alpha_{w}+\beta_{w} \log \left(\frac{\sigma}{\mu(1-\omega)}\right) \\
\delta=\alpha_{r}+\beta_{r} \log \left(\frac{\sigma}{\mu(1-\omega)}\right)
\end{gathered}
$$


where the $\alpha$ 's and $\beta$ 's are constants. Throughout these equations, although it is taken as zero for our purposes here, $\omega$ is the damage parameter.

The governing principles of the analysis are:

(1) From the constitutive equations given above, use of Eq. 1 with Eqs. 2 define the shape of the steady state creep response with stress. Differences in the steady state response of different materials will be reflected as changes in the values of those parameters that are not fixed by theoretical considerations.

(2) Eq. 4 is the mathematical representation of the transient strain curves depicted graphically in Figure 3, which produce a family of curves in stress. Moreover, the steady state strain rate always increases as the stress is increased, as determined from the steady state equations for the three mechanisms in Eqs. 2. In addition, the absolute strain value of the state parameter at steady state creep, which is the transient strain limit given by Eq. 6, increases as the stress increases. These observations can be interpreted in terms of incremental creep test results. As can be determined, all of the possible transient strain and strain rate states for any states of progressively increasing stress are above and to the left of the steady state condition in Figure 3. Therefore, just as the limit of any individual transient creep curve is the steady state creep rate, the limit of creep along all of the family of curves is a steady state creep condition so long as the stress changes progressively increase. Thus, we can state as a general principle, the lower bound of the collection of creep rates of incremental tests where the stress changes are always to progressively higher stresses tends toward (approaches) the steady state creep rate as a function of stress.

(3) Decreases in the stress during incremental tests present a more difficult situation. In fact, any given stress decrease may result in moving to the new transient strain curve either above or below the steady state creep rate. Unless the duration of the increment is long, one may not know with any certainty whether the creep rate is decreasing or increasing; i.e., whether the steady state rate is being approached from above (workhardening) or below (recovery) in Figure 3. As a result, creep rates measured after a stress decrease generally may be difficult to interpret and frequently cannot be used in determining steady state conditions. As a result, to be conservative, in this analysis, increments after a stress drop are ignored.

(4) Temperature changes normally will not cause interpretation difficulties, except when a temperature decrease occurs when a specimen is very near or in steady state creep or when the temperature decrease is marked. Temperature increases cause the strain rate to increase so that even when the specimen is in steady state creep the new strain rate will always be initially above the equilibrium condition or in workhardening. However, temperature decreases may cause the new strain rate to fall well below the equilibrium condition or into a recovery condition. Thus, one must be careful when utilizing data from temperature decreases to assure that the change did not induce a recovery condition.

Fundamentally, salt creep behavior has common micromechanical constitutive features regardless of the origin of the salt, all that differs is the exact value of the parameters. In particular, those critical parameters that primarily distinguish one salt material from another 
salt material are the steady state responses as represented by the structure factors (A's and B's) and the transient strain rate limits $\left(\varepsilon^{*}\right)$ as represented by $K_{0}$. By using the analysis criteria given above and the known behavior from the well-documented tests of WIPP clean salt as a baseline response, it may be possible on the one hand to construct reasonable steady state responses for the domal salts. On the other hand, determination of the transient strain limit depends critically upon having the complete transient strain curves, i.e., complete conventional raw creep curves. In the absence of these curves, only rather uncertain estimates can be made for values for this parameter. Often, the only recourse in this case is to estimate the transient strain limit values based on the particle impurity level and the measured values from the WIPP clean and argillaceous salts. Remaining parameters are either unaffected by or insensitive to the specific salt material.

Some comment is necessary on the nature of the bound determined from incremental test data. This is a consequence of the fact that any bound formed by incremental data alone may be still well removed from the actual steady state response. The uncertainty is such that the apparent bound will always be greater than the actual steady state response. Consequently, when the construction of the steady state response involves a series of tests that include both incremental and conventional tests, the conventional tests will be the dominant data in the determination. When the database is solely composed of incremental test data, caution must be used. 


\subsection{DOMAL SALT DATABASE}

There exists a relatively sparse creep test database for eight Gulf Coast salt domes, five that are associated with the SPR. Most, but not all, of the creep data results on domal salt were obtained from incremental tests. The tests were all performed under conditions of triaxial compression. A summary of these tests for all eight sites is given in Table $\mathrm{I}$. While this appears to be a significant array of tests, some of the data from the incremental tests cannot be instrumental in defining the bound and are therefore effectively not used in the analysis.

Table I. Summary of Creep Tests on Domal Salts.

\begin{tabular}{|c|c|c|c|c|c|}
\hline \multirow[t]{2}{*}{ Dome } & \multirow[t]{2}{*}{ Specimen } & \multicolumn{2}{|c|}{ Identifying Location } & \multirow[t]{2}{*}{ Type of Test } & \multirow[t]{2}{*}{ Notes } \\
\hline & & Type No. & $\begin{array}{l}\text { Depth } \\
\text { (m) }\end{array}$ & & \\
\hline Weeks Island, LA & $\begin{array}{l}\text { WI } 1 \\
\text { WI } 2 \\
\text { WI } 3 \\
\text { WI } 4\end{array}$ & $\begin{array}{c}\text { Core - Borehole \#3 } \\
\text { “ } \\
\text { “ }\end{array}$ & & $\begin{array}{l}\text { Conventional } \\
\text { Increment (2) } \\
\text { Conventional } \\
\text { Conventional }\end{array}$ & [1] \\
\hline West Hackberry, LA & $\begin{array}{l}\text { WH1 } \\
\text { WH2 } \\
\text { WH3 } \\
\text { WH4 } \\
\text { WH5 } \\
\text { WH6 }\end{array}$ & $\begin{array}{c}\text { Core - Well 6C } \\
، \\
، \\
\text { Core - Well } 108 \\
\text { " }\end{array}$ & $\begin{array}{r}684 \\
671 \\
678 \\
669 \\
691 \\
1113\end{array}$ & $\begin{array}{l}\text { Conventional } \\
\text { Conventional } \\
\text { Conventional } \\
\text { Conventional } \\
\text { Increment (5) } \\
\text { Increment (6) }\end{array}$ & [3] \\
\hline Big Hill, TX & $\begin{array}{l}\mathrm{BH} 1 \\
\mathrm{BH} 2 \\
\mathrm{BH} 3\end{array}$ & $\begin{array}{l}\text { Core-Well 106B } \\
\text { Core-Well 108B }\end{array}$ & $\begin{array}{r}1666 \\
767 \\
1072\end{array}$ & $\begin{array}{l}\text { Increment (4) } \\
\text { Increment (4) } \\
\text { Increment (5) }\end{array}$ & {$[4]$} \\
\hline Bayou Choctaw, LA & $\mathrm{BCl}$ & Core-Well 19A & 786 & Increment (13) & [3] \\
\hline Bryan Mound, TX & $\begin{array}{l}\text { BM1 } \\
\text { BM2 } \\
\text { BM3 } \\
\text { BM4 } \\
\text { BM5 } \\
\text { BM7 } \\
\text { BM6 } \\
\text { BM8 } \\
\text { BM9 }\end{array}$ & $\begin{array}{c}\text { Core - Well 107A } \\
\text { Core-Well 107C } \\
\text { “ } \\
\text { Core-Well 108B } \\
\text { Core-Well 107C } \\
\text { “ }\end{array}$ & $\begin{array}{r}1209 \\
1209 \\
764 \\
763 \\
1013 \\
767 \\
767 \\
764 \\
764\end{array}$ & $\begin{array}{l}\text { Increment (2) } \\
\text { Conventional } \\
\text { Conventional } \\
\text { Conventional } \\
\text { Increment (6) } \\
\text { Increment (2) } \\
\text { Increment (3) } \\
\text { Increment (2) } \\
\text { Increment (14) }\end{array}$ & {$[3]$} \\
\hline
\end{tabular}


Table I. Summary of Creep Tests on Domal Salts (Cont.).

\begin{tabular}{|c|c|c|c|c|c|}
\hline \multirow[t]{2}{*}{ Dome } & \multirow[t]{2}{*}{ Specimen } & \multicolumn{2}{|c|}{ Identifying Location } & \multirow[t]{2}{*}{ Type of Test } & \multirow[t]{2}{*}{ Notes } \\
\hline & & Type No. & $\begin{array}{c}\text { Depth } \\
\text { (m) }\end{array}$ & & \\
\hline & BM10 & Core - Well 113B & 1288 & Increment (10) & \\
\hline Jennings Dome, LA & JD1 & Core - Hole LA-1 & 1197 & Increment (5) & [6] \\
\hline Moss Bluff, TX & MV1 & Core - Hole 2 & 1021 & Increment (4) & {$[7]$} \\
\hline Avery Island, LA & (55) & Underground & 274 & Conventional & {$[8]$} \\
\hline \multicolumn{6}{|c|}{$\begin{array}{l}\text { Notes: [1] Mellegard and Pfeifle, } 1996 \text { [2] Wawersik, et al., 1980b [3] Wawersik and } \\
\text { Zeuch, } 1984 \text { [4] Wawersik, 1985 [5] Wawersik, et al., 1980a [6] Wawersik and } \\
\text { Zimmerer, 1994 [7] Wawersik, } 1992 \text { [8] DeVries, } 1988 \text { (55 tests) }\end{array}$} \\
\hline
\end{tabular}

Creep data available for each of the eight individual domal sites will be analyzed separately, before general comparisons are discussed. In presentation of the data, it should be remembered that creep data contains considerable uncertainty or scatter, typically as much as a factor of two, although sometimes more, among tests on the same material. The reported test data of stress, temperature, and the final creep rate for a given increment for seven of the sites are reproduced in Table II. These data will be used to generate the analysis for steady state creep.

Table II. Creep Data from Tests on Domal Salts.

\begin{tabular}{lcccccccc}
\hline Dome & Specimen & $\begin{array}{c}\text { Increment } \\
\text { No. }\end{array}$ & \multicolumn{2}{c}{$\begin{array}{c}\text { Increment } \\
\text { Stress }\end{array}$} & $\begin{array}{c}\text { Final Rate } \\
(\mathrm{MPa})\end{array}$ & $\begin{array}{c}\text { Temp. } \\
\left(10^{-10} / \mathrm{s}\right)\end{array}$ & $\begin{array}{c}\text { Stress Change } \\
\text { Direction }\end{array}$ & $\begin{array}{c}\text { Notes } \\
\text { (Table I) }\end{array}$ \\
\hline \multirow{3}{*}{ Weeks Island } & WI 1 & 1 & 20.0 & 27.5 & 25 & Constant & {$[1]$} \\
& WI 2 & 1 & 15 & 8.39 & 25 & - & \\
& & 2 & 15 & 391.0 & 90 & Temp. up & \\
& WI 3 & 1 & 15 & 9.73 & 25 & Constant \\
& WI 4 & 1 & 10 & 0.665 & 25 & Constant \\
\end{tabular}


Table II. Creep Data from Tests on Domal Salts (Cont.).

\begin{tabular}{|c|c|c|c|c|c|c|c|}
\hline \multirow[t]{2}{*}{ Dome } & \multirow[t]{2}{*}{ Specimen } & \multirow{2}{*}{$\begin{array}{l}\text { Increment } \\
\text { No. }\end{array}$} & \multicolumn{2}{|c|}{ Increment } & \multirow{2}{*}{$\begin{array}{l}\text { Temp. } \\
\left({ }^{\circ} \mathrm{C}\right)\end{array}$} & \multirow{2}{*}{$\begin{array}{l}\text { Stress Change } \\
\text { Direction }\end{array}$} & \multirow{2}{*}{$\begin{array}{l}\text { Notes } \\
\text { (Table I) }\end{array}$} \\
\hline & & & $\begin{array}{l}\text { Stress } \\
\text { (MPa) }\end{array}$ & $\begin{array}{r}\text { Final Rate } \\
\left(10^{-10} / \mathrm{s}\right)\end{array}$ & & & \\
\hline \multirow[t]{4}{*}{ West Hackberry } & y WH1 & 1 & 20.4 & 94.7 & 22 & Constant & {$[2$} \\
\hline & WH2 & 1 & 20.0 & 723.0 & 60 & Constant & \\
\hline & WH3 & 1 & 20.0 & 119.0 & 22 & Constant & \\
\hline & WH4 & 1 & 19.9 & 597.0 & 60 & Constant & \\
\hline \multirow[t]{11}{*}{ West Hackberry } & WH5 & 1 & 20.7 & 596.0 & 60 & - & [3] \\
\hline & & 2 & 18.8 & 130.0 & 60 & Stress down & \\
\hline & & 3 & 16.8 & 20.8 & 60 & Stress down & \\
\hline & & 4 & 14.0 & 0.30 & 60 & Stress down & \\
\hline & & 5 & 14.0 & 38.0 & 80 & Temp. up & \\
\hline & WH6 & 1 & 13.6 & 88.0 & 60 & - & \\
\hline & & 2 & 16.8 & 248.0 & 60 & Stress up & \\
\hline & & 3 & 16.8 & 659.0 & 80 & Temp. up & \\
\hline & & 4 & 17.0 & 163.0 & 60 & Temp. down & \\
\hline & & 5 & 20.2 & 619.0 & 60 & Stress up & \\
\hline & & 6 & 16.7 & 275.0 & 60 & Stress down & \\
\hline \multirow[t]{14}{*}{ Big Hill } & BH1 & 1 & 14.9 & 103.0 & 60 & - & [4] \\
\hline & & 2 & 15.0 & 402.4 & 80 & Temp. up & \\
\hline & & 3 & 15.1 & 137.8 & 60 & Temp. down & \\
\hline & & 4 & 17.9 & 364.0 & 60 & Stress up & \\
\hline & $\mathrm{BH} 2$ & 1 & 14.4 & 119.0 & 60 & - & \\
\hline & & 2 & 14.4 & 437.0 & 80 & Temp. up & \\
\hline & & 3 & 14.5 & 221.0 & 60 & Temp. down & \\
\hline & & 4 & 17.3 & 479.0 & 60 & Stress up & \\
\hline & BH3 & 1 & 15.1 & 142.0 & 60 & - & \\
\hline & & 2 & 15.1 & 271.0 & 70 & Temp. up & \\
\hline & & 3 & 15.1 & 132.3 & 60 & Temp. down & \\
\hline & & 4 & 17.9 & 363.0 & 60 & Stress up & \\
\hline & & 5 & 17.9 & 834.0 & 70 & Temp. up & \\
\hline & & 6 & 17.9 & 446.0 & 60 & Temp. down & \\
\hline \multirow[t]{5}{*}{ Bayou Choctaw } & $\mathrm{BC} 1$ & 1 & 14.7 & 34.9 & 60 & - & [3] \\
\hline & & 2 & 14.7 & 81.6 & 80 & Temp. up & \\
\hline & & 3 & 12.8 & 8.0 & 80 & Stress down & \\
\hline & & 4 & 14.7 & 66.0 & 80 & Stress up & \\
\hline & & 5 & 12.6 & 4.6 & 80 & Stress down & \\
\hline
\end{tabular}


Table II. Creep Data from Tests on Domal Salts (Cont.).

\begin{tabular}{|c|c|c|c|c|c|c|c|}
\hline \multirow[t]{2}{*}{ Dome } & \multirow[t]{2}{*}{ Specimen } & \multirow{2}{*}{$\begin{array}{l}\text { Increment } \\
\text { No. }\end{array}$} & \multicolumn{2}{|c|}{ Increment } & \multirow{2}{*}{$\begin{array}{c}\text { Temp. } \\
\left({ }^{\circ} \mathrm{C}\right)\end{array}$} & \multirow{2}{*}{$\begin{array}{l}\text { Stress Change } \\
\text { Direction }\end{array}$} & \multirow{2}{*}{$\begin{array}{l}\text { Notes } \\
\text { (Table I) }\end{array}$} \\
\hline & & & $\begin{array}{l}\text { Stress } \\
\text { (MPa) }\end{array}$ & $\begin{array}{r}\text { Final Rate } \\
\left(10^{-10} / \mathrm{s}\right)\end{array}$ & & & \\
\hline & & 6 & 14.7 & 55.0 & 80 & Stress up & \\
\hline & & 7 & 14.7 & 11.3 & 60 & Temp. down & \\
\hline & & 8 & 17.1 & $?$ & 60 & Stress up & \\
\hline & & 9 & 14.8 & 6.8 & 60 & Stress down & \\
\hline & & 10 & 17.0 & 37.0 & 60 & Stress up & \\
\hline & & 11 & 14.9 & 4.7 & 60 & Stress down & \\
\hline & & 12 & 17.1 & 37.0 & 60 & Stress up & \\
\hline & & 13 & 14.8 & 1.0 & 60 & Stress down & \\
\hline \multirow[t]{5}{*}{ Bryan Mound } & BM1 & 1 & 10.1 & 2.52 & 60 & - & [5] \\
\hline & & 2 & 21.6 & 22.0 & 60 & Stress up & \\
\hline & BM2 & 1 & 20.8 & 9.0 & 60 & Constant & \\
\hline & BM3 & 1 & 20.6 & 27.5 & 22 & Constant & \\
\hline & BM4 & 1 & 20.6 & 12.4 & 22 & Constant & \\
\hline \multirow[t]{22}{*}{ Bryan Mound } & BM5 & 1 & 20.6 & 92.0 & 22 & - & [3] \\
\hline & & 2 & 21.1 & 41.0 & 22 & Stress+delta & \\
\hline & & 3 & 20.5 & 27.0 & 22 & Stress-delta & \\
\hline & & 4 & 19.9 & 87.0 & 60 & Temp. up & \\
\hline & & 5 & 19.5 & 969.0 & 100 & Temp. up & \\
\hline & & 6 & 20.1 & 49.0 & 60 & Temp. down & \\
\hline & BM6 & 1 & 16.0 & 28.1 & 60 & - & \\
\hline & & 2 & 16.2 & 27.8 & 60 & Stress+delta & \\
\hline & & 3 & 22.6 & 66.9 & 60 & Stress up & \\
\hline & BM7 & 1 & 20.9 & 21.2 & 22 & - & \\
\hline & & 2 & 20.9 & 55.9 & 60 & Temp. up & \\
\hline & BM8 & 1 & 14.2 & 16.0 & 60 & - & \\
\hline & & 2 & 21.7 & 110.0 & 60 & Stress up & \\
\hline & BM9 & 1 & 14.0 & 11.0 & 60 & - & \\
\hline & & 2 & 14.1 & 26.0 & 80 & Temp. up & \\
\hline & & 2 & 14.4 & 27.0 & 80 & Stress+delta & \\
\hline & & 4 & 14.4 & 6.0 & 60 & Temp down & \\
\hline & & 5 & 15.4 & 7.4 & 60 & Stress up & \\
\hline & & 6 & 15.3 & 24.0 & 80 & Temp. up & \\
\hline & & 7 & 15.3 & 4.7 & 60 & Temp down & \\
\hline & & 8 & 20.6 & 43.0 & 60 & Stress up & \\
\hline & & 9 & 20.5 & 91.4 & 80 & Temp. up & \\
\hline
\end{tabular}


Table II. Creep Data from Tests on Domal Salts (Cont.).

\begin{tabular}{|c|c|c|c|c|c|c|c|}
\hline \multirow[t]{2}{*}{ Dome } & \multirow[t]{2}{*}{ Specimen } & \multirow{2}{*}{$\begin{array}{l}\text { Increment } \\
\text { No. }\end{array}$} & \multicolumn{2}{|c|}{ Increment } & \multirow{2}{*}{$\begin{array}{c}\text { Temp. } \\
\left({ }^{\circ} \mathrm{C}\right) \\
\end{array}$} & \multirow{2}{*}{$\begin{array}{l}\text { Stress Change } \\
\text { Direction }\end{array}$} & \multirow{2}{*}{$\begin{array}{l}\text { Notes } \\
\text { (Table I) }\end{array}$} \\
\hline & & & $\begin{array}{l}\text { Stress } \\
(\mathrm{MPa})\end{array}$ & $\begin{array}{r}\text { Final Rate } \\
\left(10^{-10} / \mathrm{s}\right)\end{array}$ & & & \\
\hline & \multirow{15}{*}{ BM10 } & 10 & 20.5 & 22.0 & 60 & Temp. down & \\
\hline & & 11 & 22.1 & 32.8 & 60 & Stress up & \\
\hline & & 12 & 24.5 & 96.0 & 60 & Stress up & \\
\hline & & 13 & 24.5 & 365.0 & 80 & Temp. up & \\
\hline & & 14 & 24.5 & 14.0 & 33.5 & Temp. down & \\
\hline & & 1 & 17.3 & 108.5 & 40 & - & \\
\hline & & 2 & 17.2 & 232.0 & 60 & Temp. up & \\
\hline & & 3 & 17.1 & 850.0 & 80 & Temp. up & \\
\hline & & 4 & 17.2 & 128.0 & 60 & Temp. down & \\
\hline & & 5 & 17.2 & 29.6 & 40 & Temp. down & \\
\hline & & 6 & 19.7 & 85.0 & 40 & Stress up & \\
\hline & & 7 & 19.6 & 328.0 & 60 & Temp. up & \\
\hline & & 8 & 19.6 & 56.3 & 40 & Temp down & \\
\hline & & 9 & 19.5 & 1258.0 & 80 & Temp. up & \\
\hline & & 10 & 19.6 & 331.6 & 60 & Temp. down & \\
\hline \multirow[t]{5}{*}{ Jennings Dome } & JD1 & 1 & 17.4 & 14.2 & 40 & - & [6] \\
\hline & & 2 & 16.3 & 9.4 & 60 & St. down, T up & \\
\hline & & 3 & 17.3 & 22.0 & 60 & Stress up & \\
\hline & & 4 & 19.7 & 34.8 & 60 & Stress up & \\
\hline & & 5 & 19.7 & 4.4 & 40 & Temp. down & \\
\hline \multirow[t]{4}{*}{ Moss Bluff } & MB1 & 1 & 16.0 & 74.2 & 40 & - & [7] \\
\hline & & 2 & 16.1 & 118.0 & 60 & Temp. up & \\
\hline & & 3 & 19.5 & 214.0 & 60 & Stress up & \\
\hline & & 4 & 19.5 & 52.1 & 40 & Temp. down & \\
\hline
\end{tabular}

Table II does not include the very extensive database on Avery Island salt [DeVries, 1988], primarily because of the extensive quantity of data in this database. These data are given later in the section on the analysis of Avery Island salt behavior because it is easier to understand them in the analysis context. It is sufficient to note here, that the creep tests on Avery Island salt were all conventional tests and permit the evaluation of all of the parameters of the M-D model, should it be necessary for the application. 
(Page left intentionally blank) 


\subsection{ANALYSIS OF CREEP DATA}

In presenting the analysis of the reported data, we begin with Weeks Island and Avery Island salts because they represent the most complete data collection in terms of the M-D model and can be compared extensively to the WIPP clean salt baseline. Then the remaining salt dome data are analyzed and compared to the extent possible to the WIPP clean salt baseline data.

\subsection{WEEKS ISLAND (WI)}

The Weeks Island salt dome geology and salt characteristics have been investigated for the SPR Project by Acres American [1977, 1979]. Petroleum storage is in the rooms and drifts of an underground salt mine previously operated in the dome, and purchased for the SPR. The salt was cored from the ground surface through shallow boreholes into the salt at several locations in the dome and the core was petrographically examined. Grain diameters were locally uniform, but varied from location to location, ranging from 3.7 to $12.7 \mathrm{~mm}(0.12$ to 0.5 inches). The salt was unusually pure with a principal impurity content of 1 to $2 \%$, consisting almost entirely of anhydrite. Small amounts of clays, hydrogen sulfide, carbon dioxide and petroleum products were detectecl. These geologic results have been summarized by Ortiz [1980]. A general geological description of the dome has been given by Neal, et al. [1993a]. The dome is thought to have several spines separated by shear zones. These zones are apparent in the mine, primarily through concentrations of impurities, however, little information is presented on their impurity content and distribution. As noted, the shear zones had higher concentrations of impurities with sandstone and marly clays dispersed in the zone.

There is very little early creep information about the Weeks Island mine. In situ room closure measurements were made in a lower level room between 1961 and 1967 that gave an approximate convergence rate of $12.7 \mathrm{~mm}(0.5$ inches) per year [Ortiz, 1980]. Because the room location and dimensions are not well specified, the closure cannot be used to determine the relative creep response of the Weeks Island salt.

Recently Mellegard and Pfeifle [1996] tested four specimens of Weeks Island salt prepared from material taken from Well No. BH-3. The borehole was not especially deep, reaching from the ground surface just into the salt. These specimens were prepared and tested under carefully specified and controlled conditions. Even though a limited number of tests were made, procedures used were sufficient to characterize nearly all of the nonthermal parameters of most relevant mechanism of the M-D model of creep (the exception is the recovery parameter). Specific attention was given to defining the steady state response through conventional creep tests. Although previously discussed, a conventional creep test in triaxial compression involves initial pressurization of the specimen, followed by a more-or-less instantaneous increase in the axial force to the deviatoric stress value chosen for the test. Thereafter, the stresses are held constant, with corrections for the changes in specimen cross section with deformation. In a conventional creep test, the temperature is also held constant. When the specified load is achieved, both time and deformation are re-set to be zero and the specimen axial and lateral (radial) deformations can then be measured as a function of time to produce the raw creep data, such as that shown in Figure 1. Here, both the axial and lateral strains are plotted. In addition the strains produced by the application of the axial load are 
measured and reported. Although not important for determining the steady state creep response, application strains have a bearing on evaluation of transient creep parameters.

Again as discussed previously, achievement of the steady state condition is difficult to determine from the raw creep data, which often causes the reporting of transient creep rates erroneously as steady state rates. This difficulty is lessened if the first derivative of the raw data (creep rate) is plotted as a function of time, as shown in Figure 2. From this plot, it is relatively easy to determine whether the creep rate is approaching the steady state rate, and to accurately estimate the asymptotic value which is the true steady state creep rate. Either a smoothed visual or exponential curve fitted to the experimental data of Figure 2 gives an asymptotic steady state rate of about $9.73 \times 10^{-10} / \mathrm{s}$. Steady state creep rates from the four creep tests are plotted in logarithmic form against the creep stress in Figure 4 . The slope of the data is just the parameter $n_{2}$, while the intercept of the line on the ordinate axis is the structure parameter, $A_{2}$. Basically, the structure factors for the other two mechanisms are determined similarly, when there are sufficient data to do so. In our case, since there are insufficient data to determine the other structure factors, we will assume that all structure factors change in the same proportion as the change in $A_{2}$ compared to the WIPP clean salt baseline.

In Figure 4, Weeks Island domal salt steady state creep data at $22^{\circ} \mathrm{C}$ are compared to the more extensive data from clean WIPP bedded salt, both with about the same impurity content. The line in the figure is actually determined from an even more extensive creep database and from independent inputs from micromechanical models that were used to establish the form and slope of the curve for the two mechanisms controlling salt creep for these conditions [Munson, et al., 1989]. The third mechanism dominant at higher temperatures is not involved here. As is apparent, Weeks Island data are very comparable to the WIPP data, except that they are offset vertically, by a factor of about $0.50(\log -0.30)$, to apparently a somewhat smaller structure factor value. However, when we consider the difference because of the temperature, $22^{\circ} \mathrm{C}$ vs. $25^{\circ} \mathrm{C}$, this itself causes a shift by a factor of $0.84(\log -0.0746)$. To compare data collected at different temperatures, we will always need to make a temperature correction. Therefore, the actual offset due to the difference in materials is only a factor of $0.59(\log -0.23)$.

Although the values of the model constants given by Munson, et al. [1989] are independent of both stress and temperature, they are not independent of those affects due to differences in material. However, whether or not the influence of temperature can be observed depends upon how the data are presented. As a result, in plots such as Figure 4 for the same material, the different temperatures will cause a shift to produce a family of curves all with similar characteristics, but offset from each other. Specifically, in the logarithmic plots that we are using here, differences caused by temperature will manifest themselves as an apparent change in intercept on the ordinate. Again, this observed temperature induced change does not translate into an actual change in the structure factors. On the other hand, however, in these plots, material differences also appear as differences in the value of the intercept, which must be interpreted as a real difference in the value of structure factor, $A$. In order to determine the material affect, it is necessary to reduce the observed responses obtained in these plots of creep data to an equivalent response at $25^{\circ} \mathrm{C}$. Then, any difference between the reduced response and the WIPP clean salt response at $25^{\circ} \mathrm{C}$ will be a true difference caused entirely by the material and can be quantified by the difference in the structure factors. 


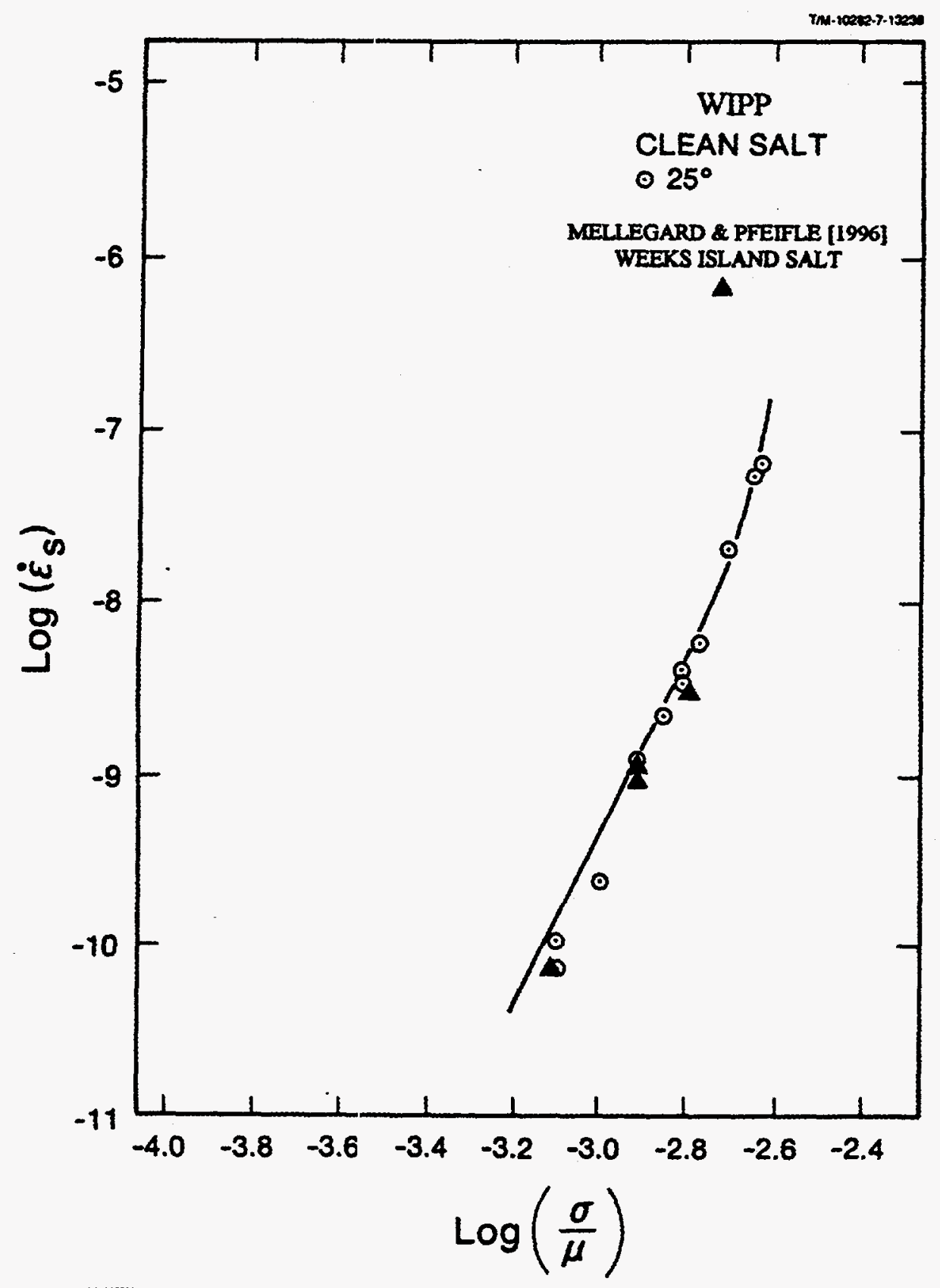

Figure 4. Steady State Response of Weeks Island and WIPP Salt [Munson and Ehgartner, 1997].

To determine the temperature corrections, we make use of the thermal activation terms for all three mechanisms of the M-D model, as given in Eqs. 2. When this is done, the calculated multiplication factor to make the correction to $25^{\circ} \mathrm{C}$ for data generated at $22^{\circ} \mathrm{C}$ is 0.84 (and the 
equivalent $\log$ is -0.0746$)$, at $40^{\circ} \mathrm{C}$ is $2.247(+0.3517)$, at $60^{\circ} \mathrm{C}$ is $5.908(+0.7715)$, at $80^{\circ} \mathrm{C}$ is $13.91(+1.143)$, and at $100^{\circ} \mathrm{C}$ is $29.88(+1.475)$.

In evaluating the steady state creep information from Weeks Island, we must discuss the question of uncertainty of individual datum and how this is modified by a larger collection of data. It is generally believed [Munson, et al., 1989] that the uncertainty in an individual steady state creep rate determination is about a factor of two, or a log difference of $+/-0.30$. Within this uncertainty, any of the Weeks Island data points would be indistinguishable from the WIPP data. However, as more data are considered, as with the four Weeks Island datum, the nature of the uncertainty changes. Larger collections of data will have close to a lognormal distribution, with the bulk of the data concentrated nearer to the lowest possible value of creep rate. Thus, the best-fit line to a collection of data does not have an uncertainty as large as a single datum. Even with the small amount of Weeks Island data presented here, the creep rates are all uniformly lower than the best representation of the WIPP data. As a consequence, this is why we believe the steady state rate of Weeks Island salt to be measurably less, although not much less, than WIPP clean salt.

Once the steady state creep rate has been determined for a given test, then Figure 1 can be used to determine transient strain limit, $\varepsilon^{*}$. A line with the steady state slope is constructed asymptotic to the creep curve on the raw creep curve and the intercept of this line on the ordinate (strain) gives the parameter. When these transient strain limit values are plotted in Figure 5 as a function of stress, the behavior appears essentially identical to that of the WIPP clean salt baseline. The intercept of the line in Figure 5 on the ordinate gives the value of the parameter $\mathrm{K}_{0}$. This means that the $\mathrm{K}_{0}$ parameter value for Weeks Island salt remains essentially unchanged from that for WIPP clean salt. Moreover, this is one of the parameters that are sensitive to the type of salt, especially to impurity content. However, there is no micromechanical model currently available that specifies how this parameter will change from material to material.

The workhardening parameter is defined as the intercept on the ordinate axis of the logarithmic plot of strain rate verses the total strain. (Although it looks similar to Figure 2, the strain plot is a more sensitive and accurate method of determining the workhardening parameter). The workhardening data for Weeks Island salt are plotted in Figure 6 in comparison to the pure WIPP salt data. Based on Figure 6 , to obtain a slightly better fit to the data, it would be acceptable to change the workhardening parameter, $\Delta$; however, it hardly seems justified considering the scatter in the data. In addition, the exact value of the parameter is not especially critical. Thus, even though there is considerable scatter, the data comparison suggests that the Weeks Island data are within reasonable agreement to the WIPP data. As a result, we will assume the same value for the Weeks Island salt as determined for the WIPP clean salt. In addition, where the data are insufficient to permit parameter determination for the other domal salts, the same value determined for the WIPP clean salt will also be assigned.

We must comment on the remainder of the M-D model parameters, even though they cannot be evaluated from the current database. Actually, most of these constants are independent of the exact salt material being considered. This results from the fact that many of these parameters are related to the salt properties and processes at an atomic level. We will assume, 


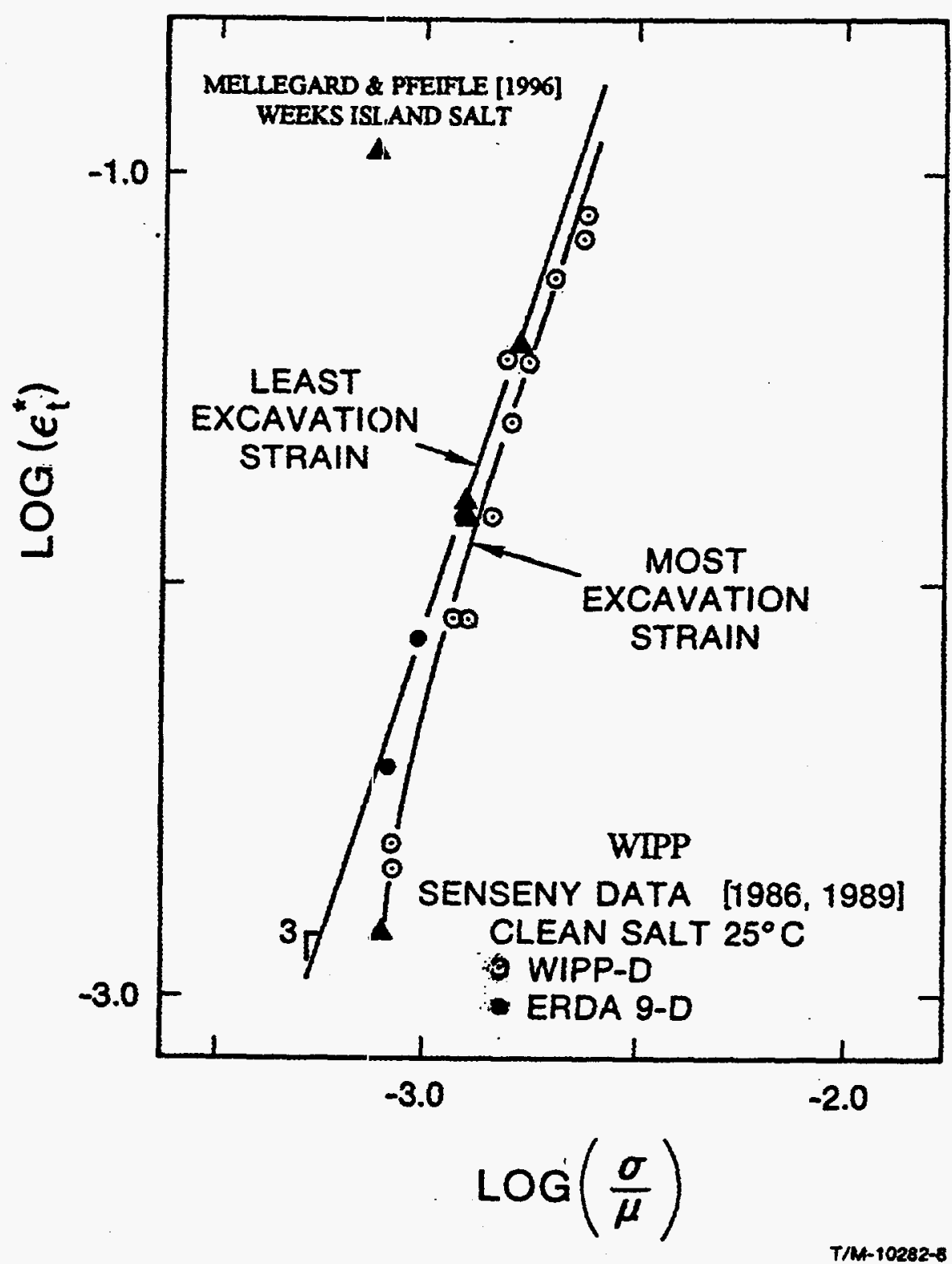

Figure 5. Transient Strain Limit for Weeks Island and WIPP Salt [Munson and Ehgartner, 1997].

based on physical arguments, that similar values of these parameters can be used for the other domal salts. The activation energies, $Q$, are related to atomic diffusion processes and are not normally sensitive to the origin differences of the various salt materials. Similarly, the stress exponents, $\mathrm{n}$, are also related to local atomic processes and are insensitive to different salt 
materials. In this case we can be quite certain based on the physical models that describe them that the values of these parameters do not change. As a result, the same values of Q's and n's that were determined for WIPP clean salt will be used for Weeks Island salt, and for the other domal salts, as well.

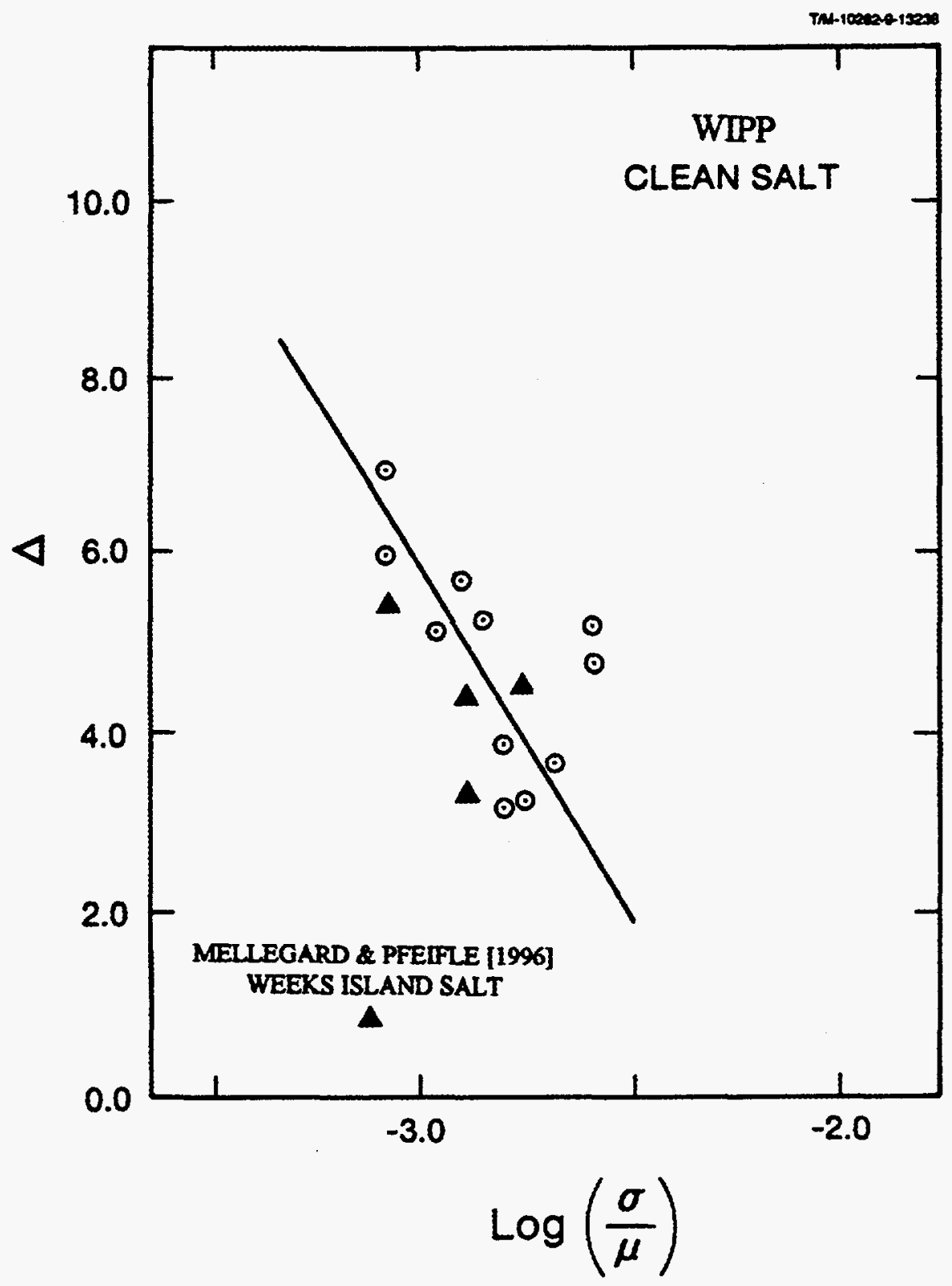

Figure 6. Workhardening Response of Weeks Island and WIPP Salt [Munson and Ehgartner, 1997]. 
Values of the stress limit, $\sigma_{0}$, and the stress constant, $q$, are not, in general, sensitive to the salt material, although they may be. In fact, stress related constants may be affected by second phase impurities that strengthen the material. However, for the low stresses involved in most of the data being analyzed, the influence of the third mechanism, which dominates at relatively large stresses, is not pronounced. Eiecause the particle impurity amounts are quite small in the salts we are dealing with in this report and the stresses are relatively low, little, if any, influence is expected on these parameters. As a consequence, the values of these parameters, $\sigma_{0}$ and $q$, from the WIPP clean salt will be used for Weeks Island and the other domal salts.

The value of $m$ is a theoretical constant, independent of material. The non-critical value of $c$ is related to an activation process and is assumed to remain unchanged with different materials.

\subsection{AVERY ISLAND (AI)}

The Avery Island dome is one of a series of domes formed along the gulf coast from the ancient Luann salt formation. As such, it has many similarities with the other domal salts treated in this paper. The dome has been mined over the many decades since shortly after the Civil War, with several different nine operators during its long history. The geology of the dome has been given by Kupfer [1963]. This indicates a relatively complex structure, with at least two distinct splines. The southeastern spline is relatively uniform with the remnants of the anhydrite bedding forming uniform sharply dipping traces in a quite pure salt. In contrast, the northwest spline appears to have sharply folded remnants of the anhydrite bedding. As shown by mining, between these two splines is a region of course salt which contains a major discontinuity.

Initiation of both the Office of Nuclear Waste Isolation (ONWI) programs for disposal of civilian reactor waste and the WIF'P program for disposal of defense generated nuclear waste resulted in the use of the Avery Island Mine for early underground studies in 1979. These studies were in anticipation of disposal of radioactive wastes in other geologic salt domes or formations [Ewing, 1981; Mellegard, 1983]. In addition to underground experiments, the mine also became a source of material for laboratory specimens. A number of cores were taken from the floor of a room at the $2.74 \mathrm{~m}(900 \mathrm{ft})$ mining level to provide specimen stock for testing [Mellegard, 1983]. This room is in the southeastern spline, but still near the horizontal center of the dome. Specimen stock was unusually clean, typically better than $98 \%$ salt, with minor amounts of anhydrite and argillaceous (clay) at the grain boundaries. Some negative crystal brine inclusions were also observed. Grain sizes averaged $7.5 \mathrm{~mm}$ ( 0.3 inches).

From these cores, a number of specimens were prepared for both creep and quasi-static testing. Results of these tests have been presented in a number of reports, primarily with analyses to obtain parameters for several constitutive models being considered by ONWI, with an eye to selecting the best model [Senseny, 1983; DeVries, 1988]. DeVries [1988] determined the parameters for these models, including the M-D model, using a statistical software procedure developed for fitting biomedical research data. Although a set of parameter values was obtained for the M-D model using this procedure, the results are basically incompatible with the micromechanical aspects of the model. As a result, these types of analysis packages probably should be avoided for sait creep data, and perhaps for creep data in general. 
The specimen stock primarily used for the laboratory creep testing was initially $406 \mathrm{~mm}$ (16 inch) diameter stock, machined to the $100 \mathrm{~mm}(3.94 \mathrm{inch})$ specimen diameter. The tests were essentially all conventional creep tests under conditions of confined compression. There were eventually a total of 55 tests for which the deformation-time results were reported [DeVries, 1988]. Results are too extensive to be repeated here, however, the reported steady state rates, transient strain limits, workhardening parameters, and test conditions are given in Table III.

Table III. Avery Island Creep Database [DeVries, 1988].

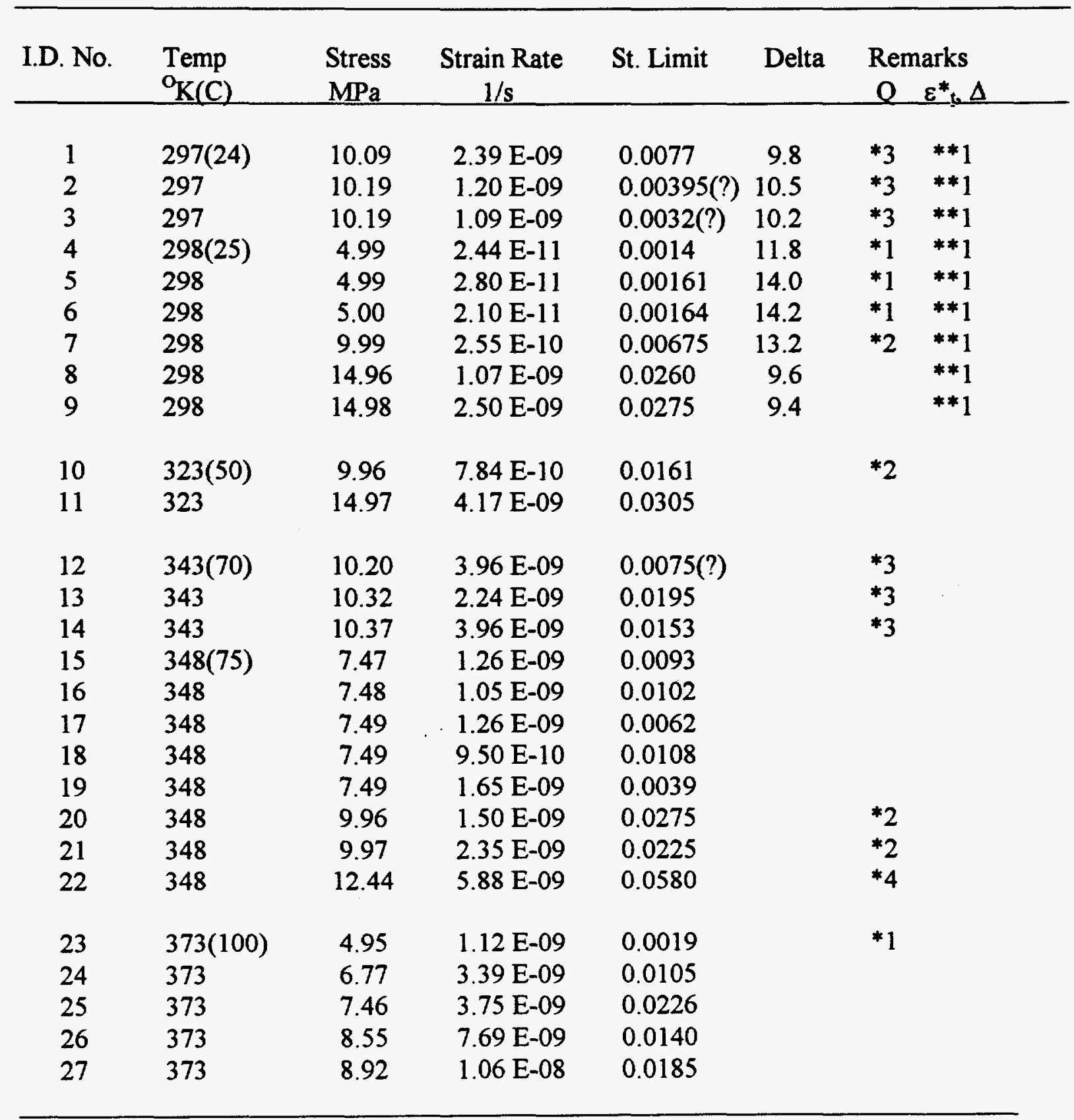


Table III. Avery Island Creep Database [DeVries, 1988] (Cont.).

\begin{tabular}{|c|c|c|c|c|c|c|}
\hline I.D. No. & $\begin{array}{l}\text { Temp } \\
\mathrm{O}_{\mathrm{K}(\mathrm{C})}\end{array}$ & $\begin{array}{l}\text { Stress } \\
\mathrm{MPa} \\
\end{array}$ & $\begin{array}{c}\text { Strain Rate } \\
1 / \mathrm{s}\end{array}$ & St. Limit & Delta & $\begin{array}{l}\text { Remarks } \\
\mathrm{Q} \quad \varepsilon^{*}, \Delta\end{array}$ \\
\hline 28 & 373 & 8.98 & $1.15 \mathrm{E}-08$ & 0.0175 & & \\
\hline 29 & 373 & 9.91 & 1.44 E-08 & 0.0530 & & *2 \\
\hline 30 & 373 & 10.10 & 1.62 E-08 & 0.0420 & & *3 \\
\hline 31 & 373 & 10.22 & 1.08 E-08 & 0.0360 & & $* 3$ \\
\hline 32 & 373 & 10.27 & $1.53 \mathrm{E}-08$ & 0.0170 & & *3 \\
\hline 33 & 373 & 12.10 & $2.50 \mathrm{E}-08$ & 0.0380 & & \\
\hline 34 & 373 & 12.30 & 4.74 E-08 & 0.0340 & & $* 4$ \\
\hline 35 & 373 & 12.35 & 3.71 E-08 & 0.0470 & & $* 4$ \\
\hline 36 & 373 & 12.37 & $3.38 \mathrm{E}-08$ & 0.0350 & & $* 4$ \\
\hline 37 & 373 & 12.39 & $2.93 \mathrm{E}-08$ & 0.0440 & & $* 4$ \\
\hline 38 & 373 & 12.40 & 3.10 E-08 & 0.0410 & & $* 4$ \\
\hline 39 & 373 & 12.46 & 2.90 E-08 & 0.0380 & & $* 4$ \\
\hline 40 & 373 & 12.49 & $4.02 \mathrm{E}-08$ & 0.0470 & & $* 4$ \\
\hline 41 & 373 & 13.57 & 3.16 E-08 & 0.0650 & & \\
\hline 42 & 373 & 13.78 & $2.81 \mathrm{E}-08$ & 0.0545 & & \\
\hline 43 & 373 & 14.70 & $5.58 \mathrm{E}-08$ & 0.0770 & & \\
\hline 44 & 373 & 16.87 & $1.11 \mathrm{E}-07$ & 0.0700 & & \\
\hline 45 & 373 & 17.20 & $1.43 \mathrm{E}-07$ & 0.0730 & & \\
\hline 46 & 373 & 19.96 & 3.55 E-07 & 0.0710 & & \\
\hline 47 & $423(150)$ & 2.99 & 5.08 E-09 & 0.0045 & & \\
\hline 48 & 423 & 4.90 & $1.84 \mathrm{E}-08$ & 0.0050 & & $* 1$ \\
\hline 49 & 423 & 6.77 & $3.97 \mathrm{E}-08$ & 0.0360 & & \\
\hline 50 & 423 & 8.82 & $4.20 \mathrm{E}-08$ & 0.0440 & & \\
\hline 51 & $473(200)$ & 3.47 & $1.36 \mathrm{E}-08$ & 0.0200 & & \\
\hline 52 & 473 & 4.71 & $3.80 \mathrm{E}-08$ & 0.0225 & & $*_{1}$ \\
\hline 53 & 473 & 6.67 & $1.21 \mathrm{E}-07$ & 0.0470 & & \\
\hline 54 & 473 & 6.78 & $1.53 \mathrm{E}-07$ & $0.0270(?)$ & & \\
\hline 55 & 473 & 9.86 & $2.48 \mathrm{E}-06$ & 0.0610 & & *2 \\
\hline
\end{tabular}

* Strain rates from these tests were used to confirm the activation energies, $Q$, at four stress levels, as denoted by the numbers in the remarks column.

** Strain rates from these tests were used to determine the values of $\varepsilon^{*}$ and $\Delta$. 
The steady state creep rates at several temperatures $\left(25,50,100\right.$, and $\left.200^{\circ} \mathrm{C}\right)$ are plotted in Figure 7. While additional data for 70,75 , and $150^{\circ} \mathrm{C}$ are not plotted for the sake of clarity, they, however, would fall into their proper positions relative to the other data, if they were plotted. The position of the WIPP $25^{\circ} \mathrm{C}$ baseline is shown (solid line). Lower temperature

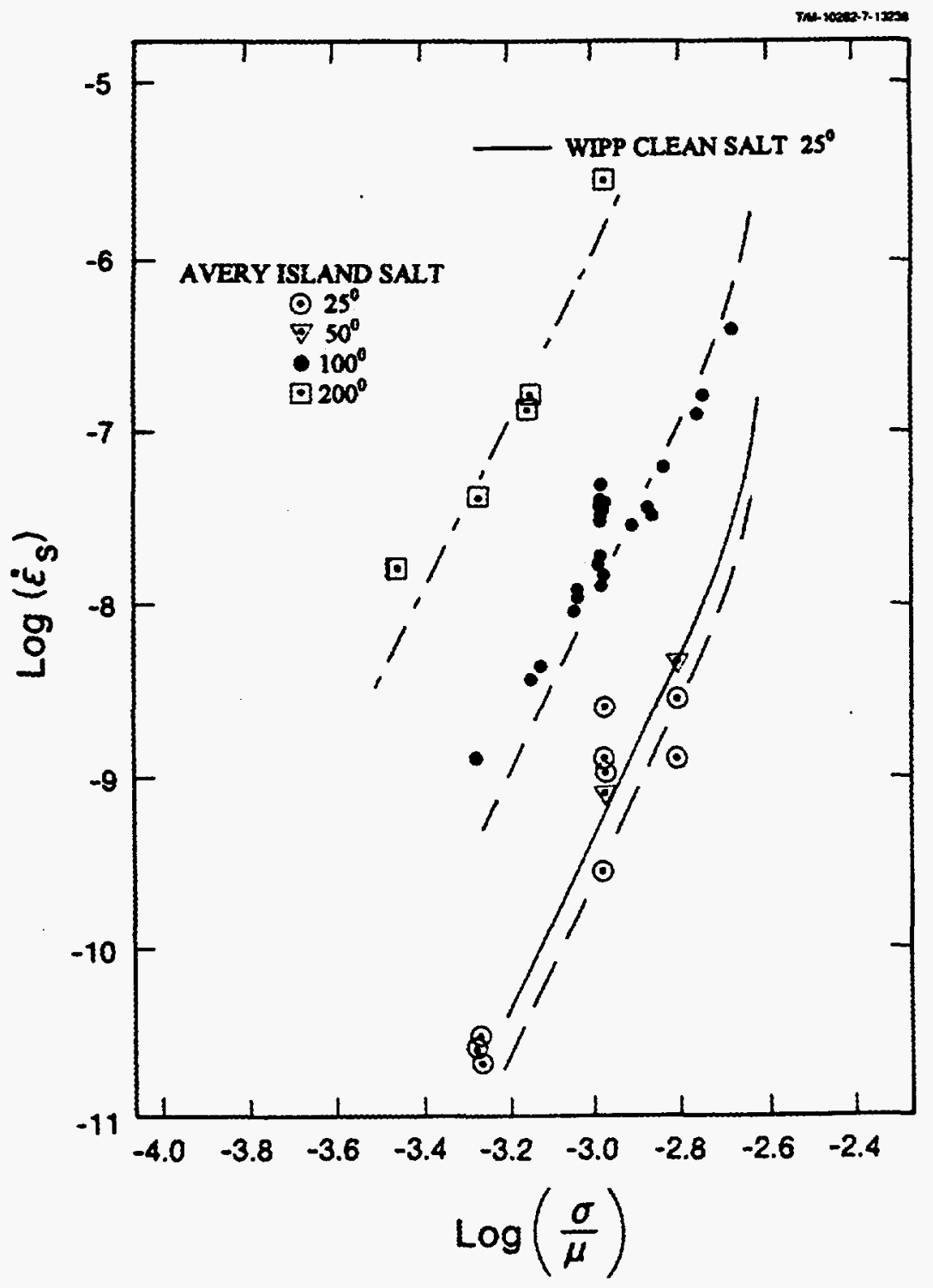

Figure 7. Steady State Response of Avery Island Domal Salt [Data of DeVries, 1988]. 
data are consistent with the slope (5.0) of the WIPP baseline. It appears that the creep of Avery Island salt is somewhat slower than the WIPP baseline, with an offset of a factor of 0.71 $(\log -0.149)$. The $50^{\circ} \mathrm{C}$ data are offset by a factor of $1.41(\log +0.149)$ from the Avery Island $25^{\circ} \mathrm{C}$ line to fall almost exactly on the WIPP baseline. The $100^{\circ} \mathrm{C}$ data are offset by a factor of $33.1(\log +1.52)$ from the $25^{\circ} \mathrm{C}$ Avery Island line, which is just slightly greater than the calculated temperature effect of a factor of $29.9(\mathrm{log}+1.475)$. A line (dot-dash) is also drawn through the $200^{\circ} \mathrm{C}$ data, however, the stope of this line (5.5) corresponds to the high temperature mechanism rather than the low temperature mechanism. Appropriate intercept values for two mechanisms are given as $6.869 \times 10^{+12}$ for $A_{2}$ and $1.137 \times 10^{+22}$ for $A_{1}$. Intercept values (B's) for the third, high stress, mechanism can not be determined directly so they are estimated by proportion between the first two mechanisms and the WIPP baseline values.

Transient strain limits for the Avery' Island salt are determined from the $25^{\circ} \mathrm{C}$ data, as plotted in Figure 8. They are consistent with the required WIPP baseline slope of 3 , but are offset upward to give an intercept $K_{0}$ of $1.342 \times 10^{+6}$. This indicates that Avery Island salt exhibits significantly greater transient strain than WIPP clean salt. In Figure 9, the experimental values of $\Delta$ are plotted against stress. While there is significant scatter, the data are not inconsistent with the WIPP baseline data. As a result, we assume that the best-fit line has the same slope as the WIPP baseline data, but with an offset to higher values of $\Delta$. Appropriate $\alpha$ and $\beta$ parameter values are determined on this basis. Although the results are not shown here, the Avery Island data are consistent with the activation energies determined from a typical Arrhenius plot for the WIPP baseline salt.

Most of the Avery Island salt parameter values for the M-D model have been determined directly from the data or are consistent with the required invariant or theoretical constant values from the WIPP baseline determination. The few parameters not either determined directly or required by the isothermal conditions are assumed to have the same values as those of the WIPP baseline salt. Because the Avery Island salt data are so extensive, the very good agreement to the WIPP baseline salt, where such agreement is required, is especially pleasing. Further, such good agreement suggests the mechanical creep behavior of Avery Island salt is well understood.

\subsection{BIG HILL (BH)}

The database for Big Hill salt is developed using stress and temperature change tests from three specimens [Wawersik, 1985]. The specimens were prepared from recovered core from two deep boreholes at the site. These boreholes were to become solutioning wells, specifically Well 106B and Well 108B. The location of the specimens taken from these wells is given in Table II. Grain sizes were from medium to quite large, ranging from $3.7 \mathrm{~mm}(0.12$ inch) to 51 $\mathrm{mm}$ (2.0 inch) with some cores having grains in excess of $100 \mathrm{~mm}$ (4.0 inch) in diameter. Although the salt purity was probably high, visual examination suggested finely distributed anhydrite crystals in the specimens from Well 106B. Magorian and Neal [1988] described the geology of the site in detail and reported insoluble contents based on density logs and $x$-ray analysis. The calculated median of insolubles from all logged holes is $1.7 \%$, probably anhydrite. Anhydrite content was greatest in Wells $110 \mathrm{~A}$ and 110B. Core samples indicated 
the occurrence of anhydrite bands parallel to the dome edges. It was believed that insoluble quantities decrease toward the edges of the dome.

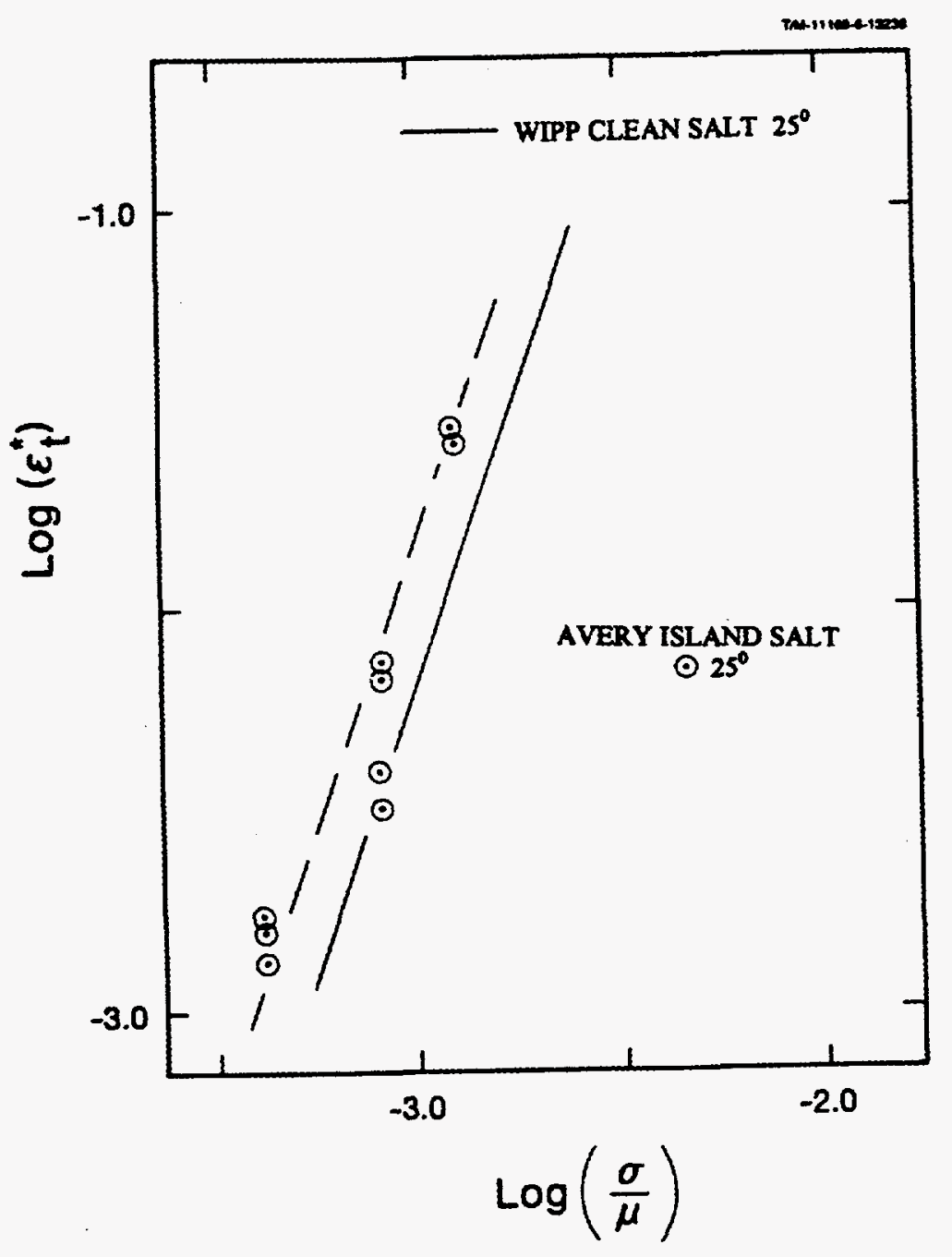

Figure 8. Transient Strain Limit of Avery Island Domal Salt [Data of DeVries, 1988]. 
As discussed previously, the creep rates reported at the end of any stress interval do not necessarily correspond to steady state creep. If the increments are all stress increases, then perhaps the smallest creep rate observed may be either close to or at the minimum creep rate for the final stress condition. A logarithmic plot of the final creep rates from each increment of

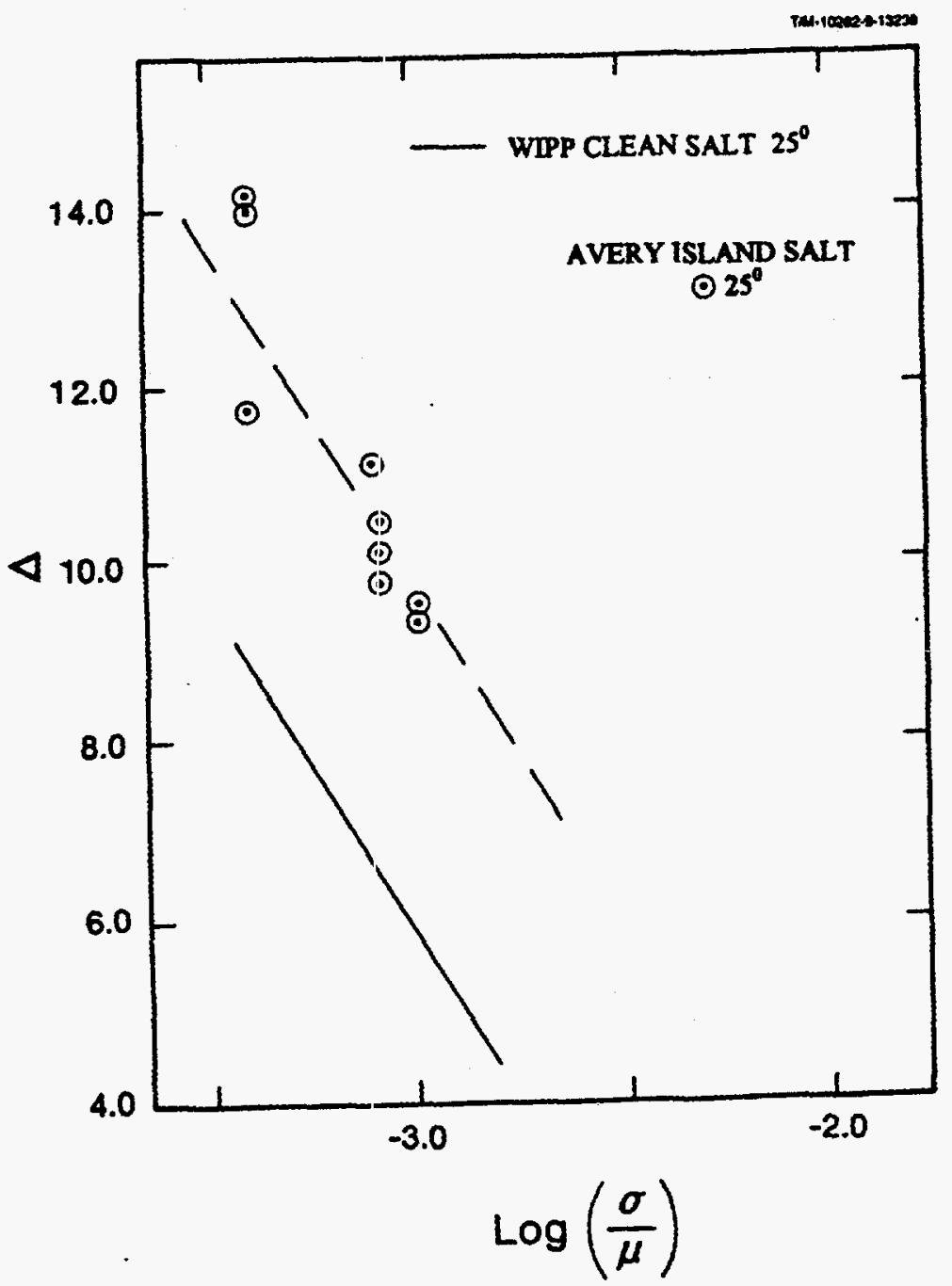

Figure 9. Delta Values of Avery Island Domal Salt [Data of DeVries, 1988]. 
these tests is given in Figure 10. A line parallel to the WIPP clean salt and just at the lowest observed creep rate from the increment tests of the Big Hill salt, shows an offset from the WIPP clean salt baseline. As indicated in the figure, the difference in the rates can found readily by measuring the vertical separation between the arrows, either as a logarithmic difference or as a ratio. Some offset is expected because of the difference in temperatures of the Big Hill and WIPP clean salt data, so to examine the true difference in creep response we need to correct for the temperature effect, as previously discussed. The $60^{\circ} \mathrm{C}$ data are offset by a factor of 8.91 (a logarithmic value of +0.95 ), which is in excess of the expected temperature correction factor of $5.89(\mathrm{log}+0.77)$ by the amount of a factor of $1.5(\log +0.18)$. The $80^{\circ} \mathrm{C}$ data are in excess of the expected temperature corrected value by a factor of $2(\log +0.31)$. As a result, the steady state creep rate of Big Hill appears to be somewhat greater than that of WIPP pure salt, and indeed also greater than that of Weeks Island salt. If the bounding envelop of data is indeed steady state, although there is no assurance of this from incremental test data, then the multiplication factor is 1.78 ( $\log$ of +0.25$)$. Thus, we suggest based on the comparisons of the two temperatures that the creep of Big Hill salt is at least 1.65 times faster (between 1.5 and 1.78) than WIPP pure salt, although it could be less. The limited creep data from Big Hill does not permit evaluation of the other creep parameters.

\subsection{WEST HACKBERRY (WH)}

General studies of the West Hackberry dome reported by Magorian, et al. [1991] essentially concentrated on the geologic characteristics of the dome. Dome impurity contents were not given.

Two separate studies of the creep of West Hackberry domal salt have been reported. In an early study [Wawersik, et al., 1980b], a total of four specimens prepared from core take from the deep borehole of solutioning Well $6 \mathrm{C}$ were tested in conventional creep tests. Dissolution tests on three separate core specimens gave an insoluble impurity content of $2.7+1-0.9 \%$, primarily anhydrite. The impurities seemed to be in bands through the specimens. The grain size was from $6 \mathrm{~mm}(0.25 \mathrm{inch})$ to $30 \mathrm{~mm}$ (1.2 inch). In these tests, we are reasonably assured that the final creep rates are the steady state rates. As shown in Figure 11, the creep rates of West Hackberry salt at $22^{\circ} \mathrm{C}$ are essentially identical to the baseline WIPP clean salt data, at least within the typical scatter. At $60^{\circ} \mathrm{C}$, the offset from the baseline data is a factor of 4.68 $(\log +0.67)$ which is only slightly less than the calculated temperature effect is a factor of 5.89 $(\log +0.77)$. Certainly, these data suggest that West Hackberry creep is very comparable to that of the WIPP clean salt and Weeks Island domal salt.

In a later study [Wawersik and Zeuch, 1984], two additional West Hackberry domal salt specimens were prepared from the core taken from Well 108. Impurities and grain sizes were comparable to the previous study. These specimens were subjected to incremental tests in which a large number of stress and temperature increments were made. Because of the large number of increments, the increment durations were quite short. Unfortunately, several of the increments were after stress drops. As the earlier discussion indicates, it is extremely difficult to analyze multiple incremental creep data, which is made even more difficult if stress drops are involved. The final creep rates at the end of each increment are plotted in Figure 12 and show the extreme range of values, as expected. However, if the final creep rates from the 


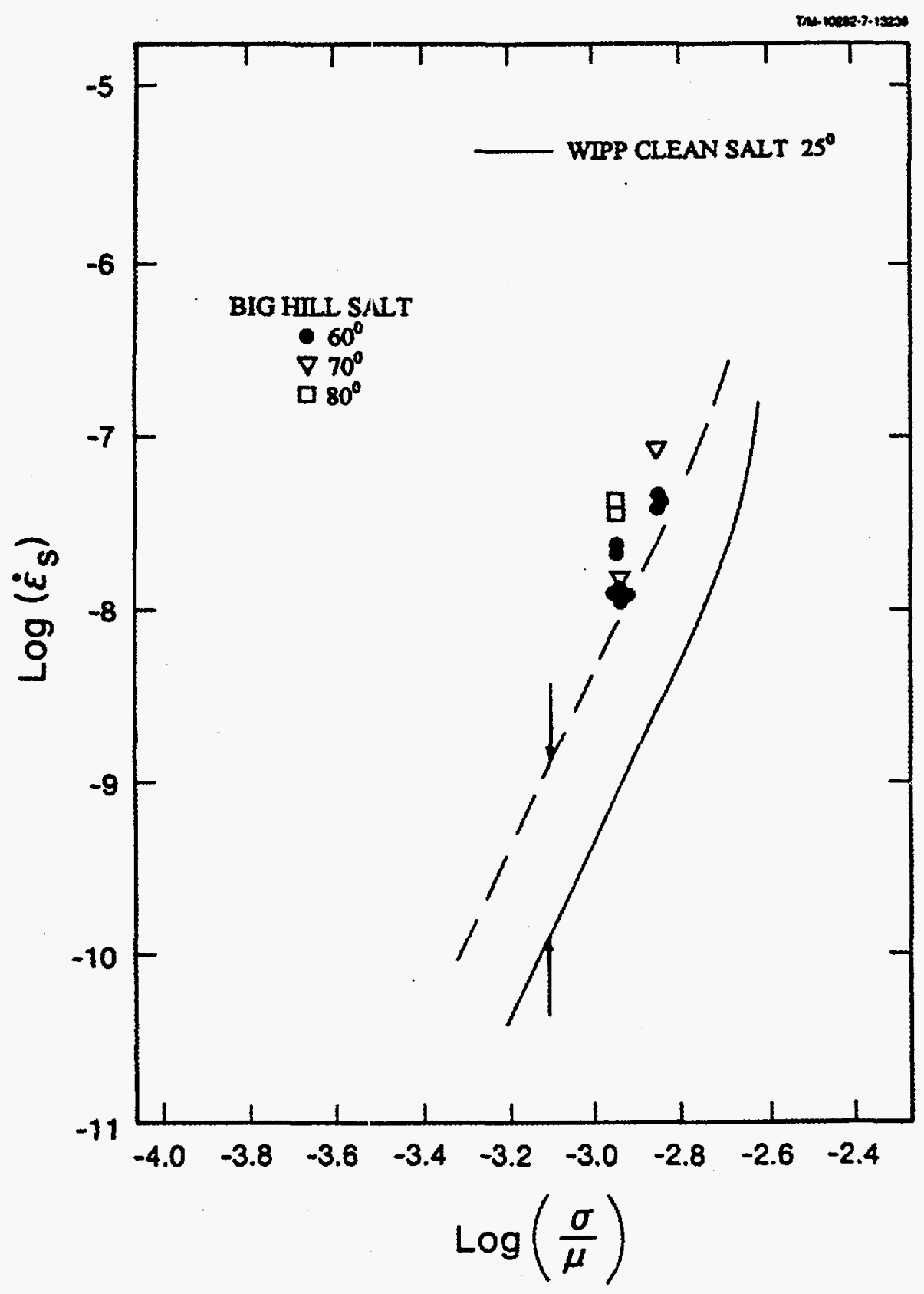

Figure 10. Steady State Creep Rates of Big Hill Domal Salt [Data of Wawersik, 1985]. 


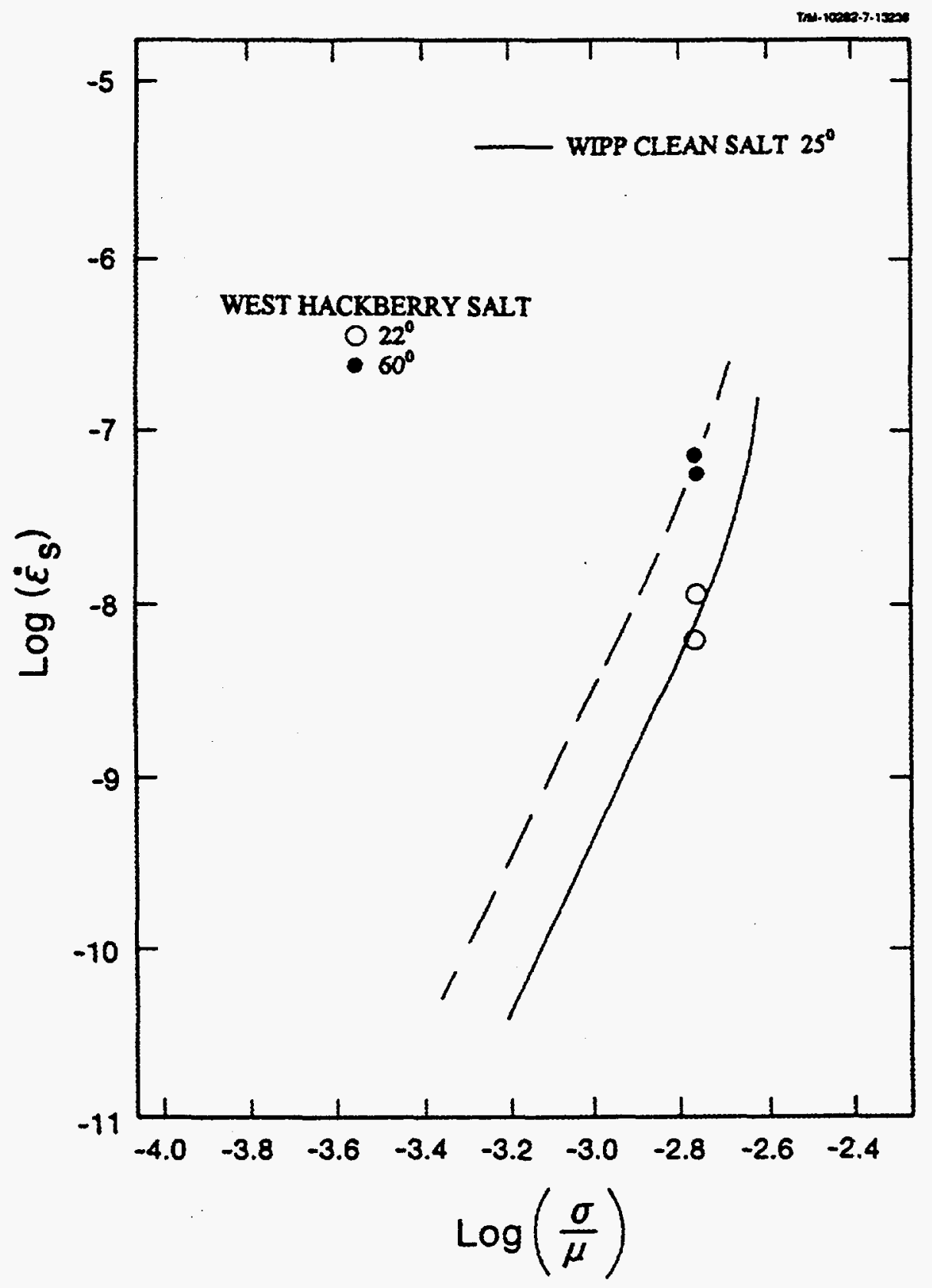

Figure 11. Conventional Test Steady State Creep Rates for West Hackberry [Data of Wawersik, et al., 1980b]. 


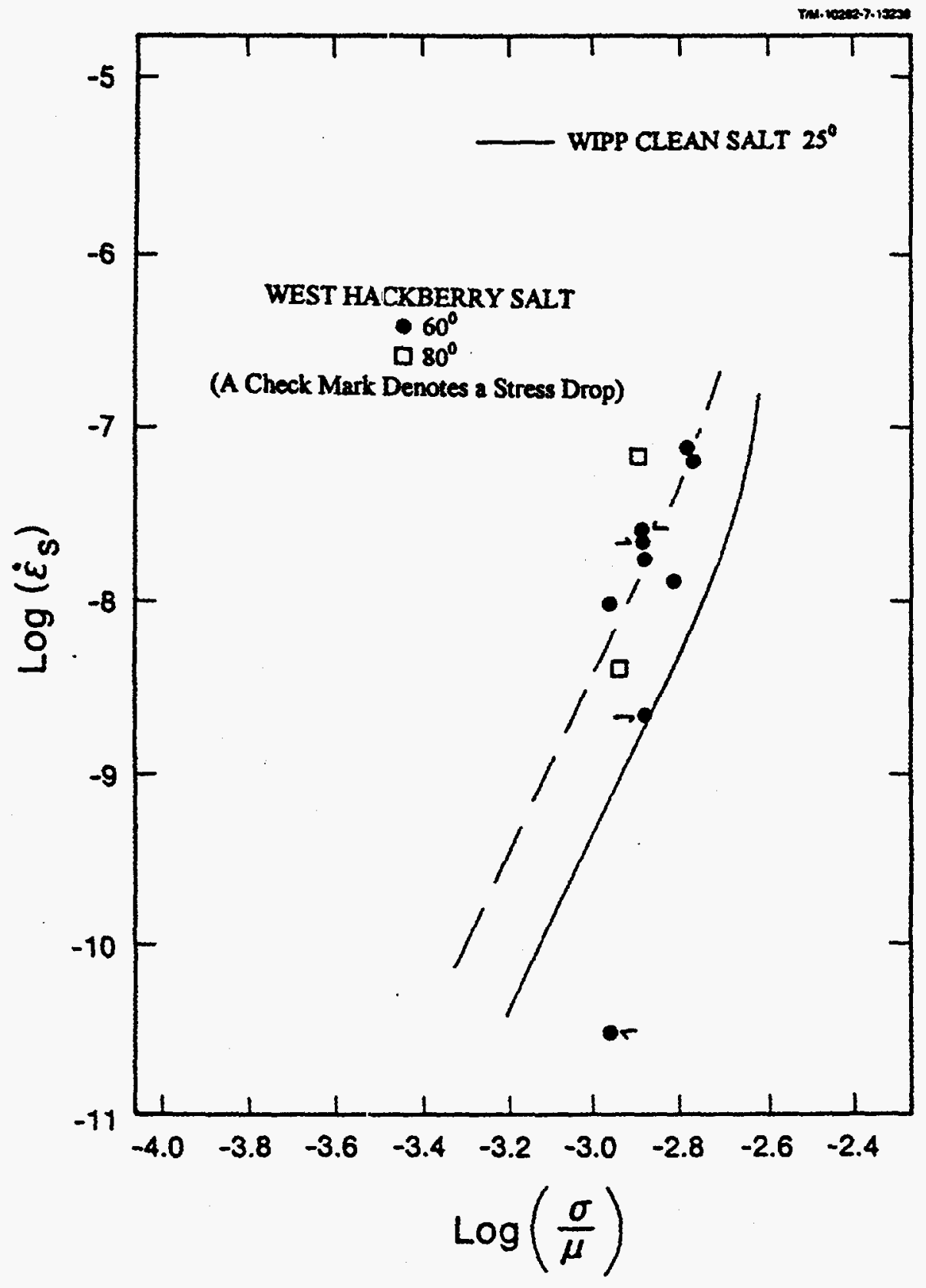

Figure 12. Incremental Test Creep Rates for West Hackberry [Data of Wawersik and Zeuch, 1984]. 
stress drop increments, which are marked with a check, are ignored, as shown in Figure 13, then the remaining data should approach the steady state rates. When these stress drop data are eliminated, the $60^{\circ} \mathrm{C}$ results are reasonably consistent with those from the earlier study discussed above. However, the data appear to have considerable scatter, perhaps as a result of difficulty in determining strain rates over the short increment durations. Although the incremental test results required elimination of inappropriate stress drop increments, the remaining incremental test data support the analysis of the earlier data which suggests a similarity between the responses of West Hackberry and WIPP clean salt creep.

\subsection{MOSS BLUFF (MB)}

One specimen was prepared from core recovered from deep Borehole 2 at the Moss Bluff dome [Wawersik, 1992]. Although an incremental test procedure was used, none of the incremental changes were stress drops. The average grain size of the specimen was $11 \mathrm{~mm}$ ( $0.4 \mathrm{inch})$. There was no indication of impurity content. The final creep rates for each of the increments are plotted in Figure 14 , where the response at $60^{\circ} \mathrm{C}$ is offset by a factor of about $5.62(\log +0.75)$ from the baseline WIPP clean salt data. This is consistent with the calculated temperature shift of a factor of $5.89(\log +0.77)$. Explanation of the $40^{\circ} \mathrm{C}$ data points is not so straightforward. While the one data point may suggest a much slower creep rate for Moss Bluff salt, it is possible that this is an erroneous data point. We will assume that the $60^{\circ} \mathrm{C}$ data are the correct response, and as a result, Moss Bluff salt steady state creep is essentially identical to the WIPP clean salt baseline data.

\subsection{BRYAN MOUND (BM)}

The geologic structure of the dome has been reported by Neal, et al. [1994]. They also included some general mineralogical information, suggesting that the anhydrite content was less than that in Big Hill. However, the shale content was thought to be greater than the domes to the east, which would encompass all of the other facilities of the SPR. The Bryan Mound specimens were prepared from stock that was obtained from coring of the same deep holes eventually used for solutioning.. The specimens had a grain size range from $2 \mathrm{~mm}(0.08 \mathrm{inch})$ to $40 \mathrm{~mm}$ (1.6 inch), with an average grain size of about $8 \mathrm{~mm}(0.3 \mathrm{inch})$. The core also exhibited high angle dark bands or concentrations of anhydrite. Anhydrite concentration determined from a limited dissolution analysis was given as about $6 \%$.

Bryan Mound was studied in two different efforts. The earlier study [Wawersik, et al., 1980a] involved four separate specimens, three of which were tested using a conventional creep method. The remaining specimen was used for a bilevel incremental test in which the stress level was increased once. Sources of this earlier specimen material were Well 107A and Well 107C. These tests should give steady state creep rates. Measured final creep rates (of the test or increment) are given in the plot of Figure 15. Although the results are somewhat confusing, they suggest that Bryan Mound salt is much more creep resistant than the WIPP clean salt, as previously noted [Wawersik, et al., 1980a]. In fact, it was difficult to fit these data because of the confusing creep rate data at the higher stress. Although there is no reason to suspect this, the data almost suggest some error in temperature. In effect, we would have to essentially discount two of the points to obtain consistent behavior in the data. 


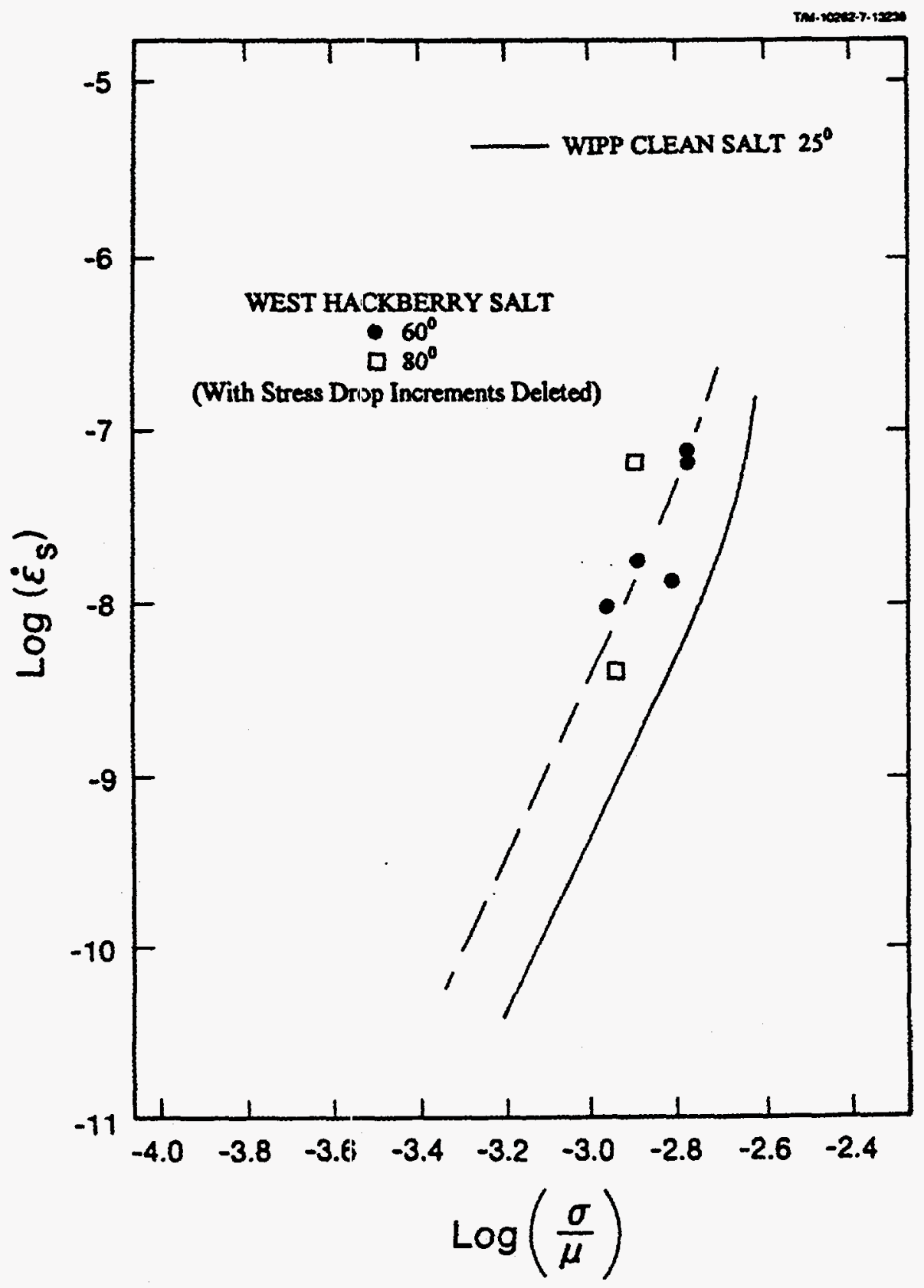

Figure 13. Incremental Test Creep Rates for West Hackberry, Stress Drops Removed [Data of Wawersik and Zeuch, 1984]. 


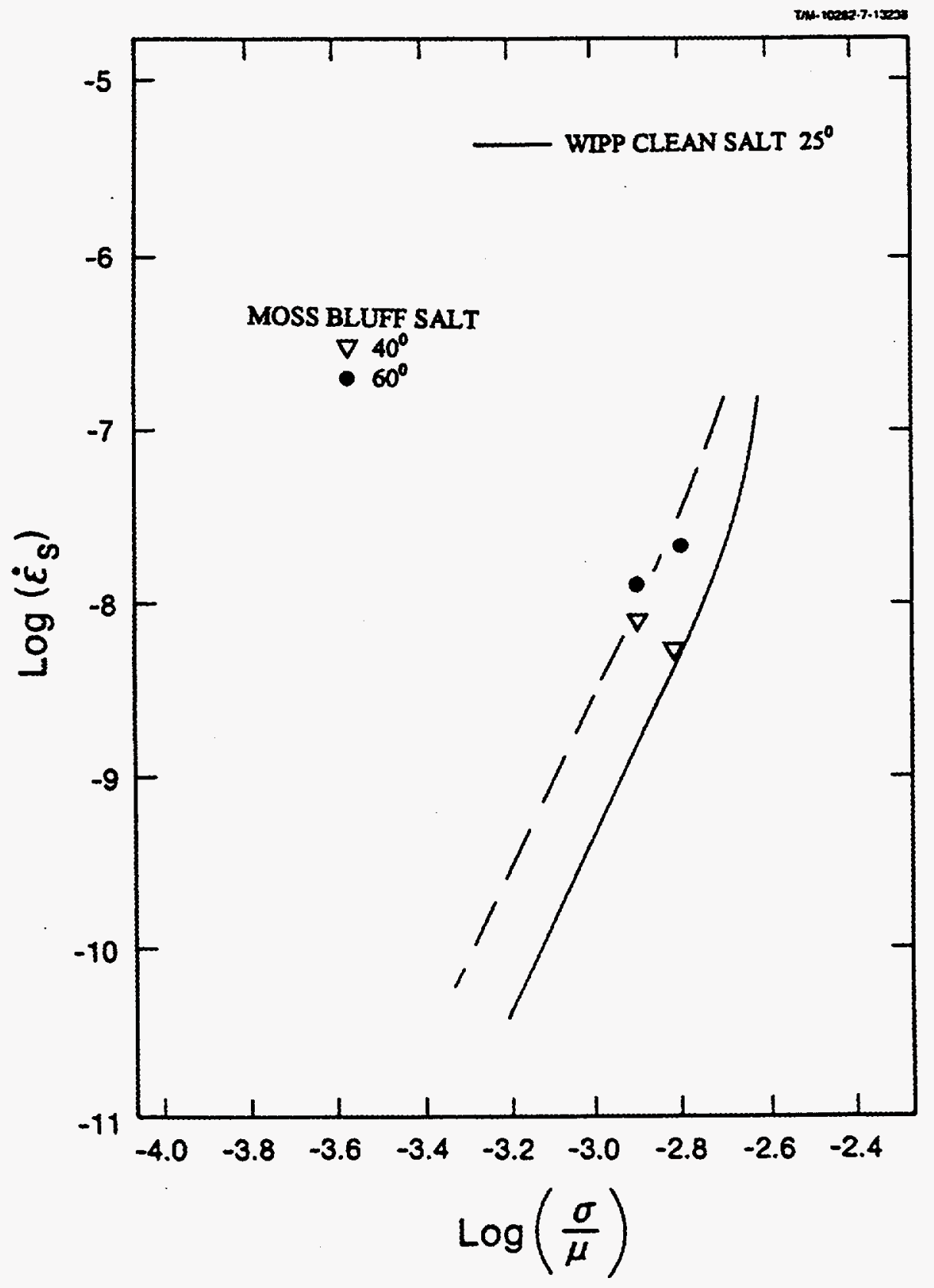

Figure 14. Incremental Test Creep Rates for Moss Bluff [Data of Wawersik, 1992]. 


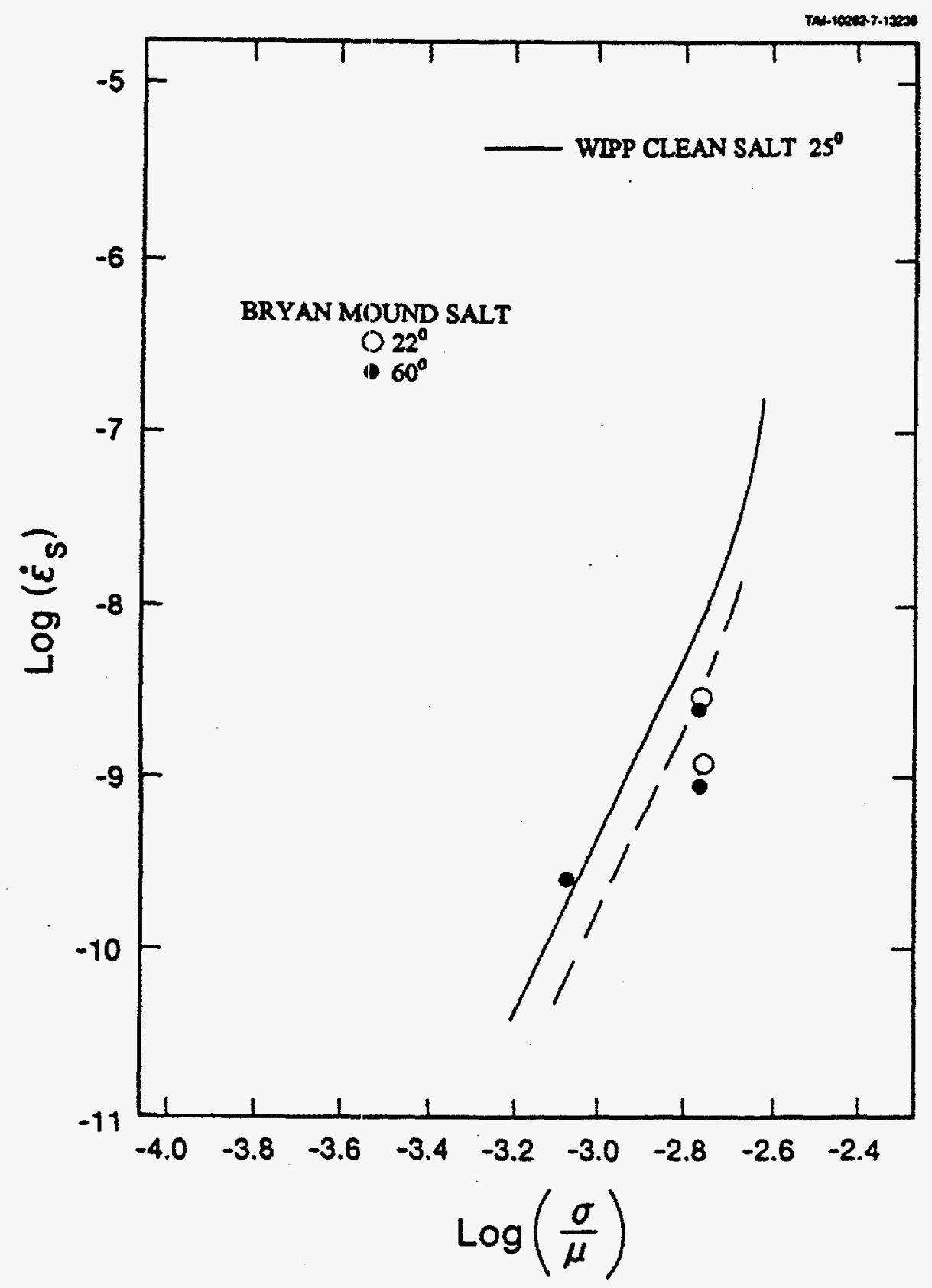

Figure 15. Conventional Test Steady State Creep Rates for Bryan Mound [Data of Wawersik, et al, 1980a]. 
We proceed under the assumption that the dashed fitted line is at least acceptable, which will be confirmed partially later by additional data. Then the $22^{\circ} \mathrm{C}$ data are offset by about a factor of $0.12(\log -0.91)$ from the WIPP clean salt baseline. Even the $60^{\circ} \mathrm{C}$ data are offset by a factor of $0.45(\log -0.35)$ below the WIPP clean salt baseline. This supports the contention that Bryan Mound salt is more creep resistant. If we look only at the Bryan Mound data, then the $60^{\circ} \mathrm{C}$ data are offset above the $22^{\circ} \mathrm{C}$ data by only about a factor of $3.55(\log +0.55)$, somewhat less than the expected factor of $5.89(\log +0.77)$.

In the later study, six specimens cored from deep boreholes were tested. Material was again primarily from Well 107C, with single specimens each from Well 108B and Well 113B. These specimens were tested using the incremental testing procedure in both stress and temperature. In four of the specimens, relatively small numbers of increments were involved in any given test, typically two. As a result, the final increment strain rates could be approaching the steady state creep rate. However, in the other two of these specimens, a relatively large number of increments, up to 14 , were used in each test, which suggests that most of the creep rates determined for most individual increments can not be in steady state. On the positive side, all of the incremental stress changes for these tests were stress increases. We analyze these creep tests in two groups. Increment final creep rates for the first four specimens are plotted in Figure 16. Again, we take the smallest creep rates as the guide for determining the appropriate steady state response. If we take the lower envelope of the rates as approaching the steady state rate, we can then construct a line parallel to the WIPP clean salt baseline data. If we consider only the effects of temperature difference on the Bryan Mound data, then the $60^{\circ} \mathrm{C}$ data are offset from the $22^{\circ} \mathrm{C}$ data by a factor of $3.16(\log +0.50)$ compared to a calculated factor of $5.89(\log +0.77)$ and the $100^{\circ} \mathrm{C}$ data are offset by a factor of $25.12(\log +1.40)$ compared to a calculated factor of $29.51(\log +1.47)$. In comparison to the WIPP clean salt baseline, the apparent steady state response for the $60^{\circ} \mathrm{C}$ Bryan Mound data is offset by a factor of 2.00 (log -0.30 ) from the baseline data, while the $22^{\circ} \mathrm{C}$ data are offset by about a factor of 6.03 ( $\log -$ 0.78 ) from the baseline.

We examine the results separately for the very complicated incremental tests performed on the final two specimens. These test results produce the final creep rates for each increment as plotted in Figure 17. There is considerable uncertainty in our ability to define steady state limits for these data. Although, in fact, the $40^{\circ} \mathrm{C}$ and $80^{\circ} \mathrm{C}$ data appear to be in the proper relationship to the $60^{\circ} \mathrm{C}$ data, if the very low creep rate data point at $40^{\circ} \mathrm{C}$ is eliminated. However, little more can be said about them. Because of the testing method, we hesitate to give an offset for the $80^{\circ} \mathrm{C}$ and $40^{\circ} \mathrm{C}$ data. Nevertheless, at $60^{\circ} \mathrm{C}$ for these two specimens, the data appear to have an offset from the WIPP clean salt data baseline by about a factor of 2.34 $(\log -0.37)$, which is essentially the same as the $60^{\circ} \mathrm{C}$ data from the four well-defined tests of this study. These offsets are also in agreement with the earlier $60^{\circ} \mathrm{C}$ data offset of a factor of $0.45(\log -0.35)$ from the WIPP baseline, described previously and given in Figure 15.

Within the restrictions of the limited database, the necessary analysis assumptions, and the undoubted experimental uncertainty, the results of the two Bryan Mound studies are in essential agreement. From these results, it appears the $22^{\circ} \mathrm{C}$ steady state creep response of Bryan Mound salt is a factor of 0.13 to 0.17 (log of -0.90 to -0.78 ) more creep resistant than WIPP clean salt, with an average calculated $25^{\circ} \mathrm{C}$ data offset by a factor of $0.17(\log -0.76)$. 


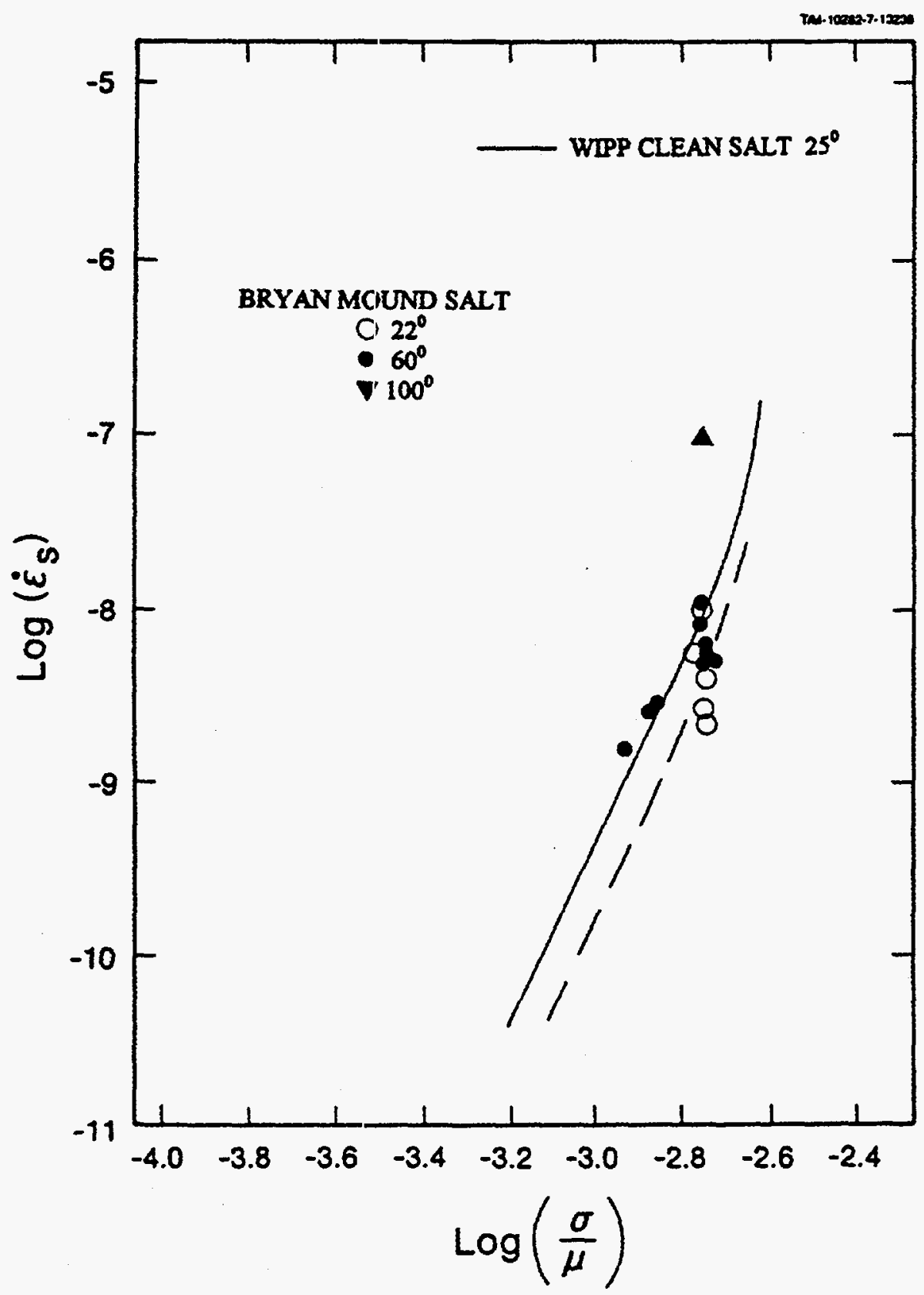

Figure 16. Incremental Test Creep Rates for Bryan Mound [Data of Wawersik and Zeuch, 1984]. 


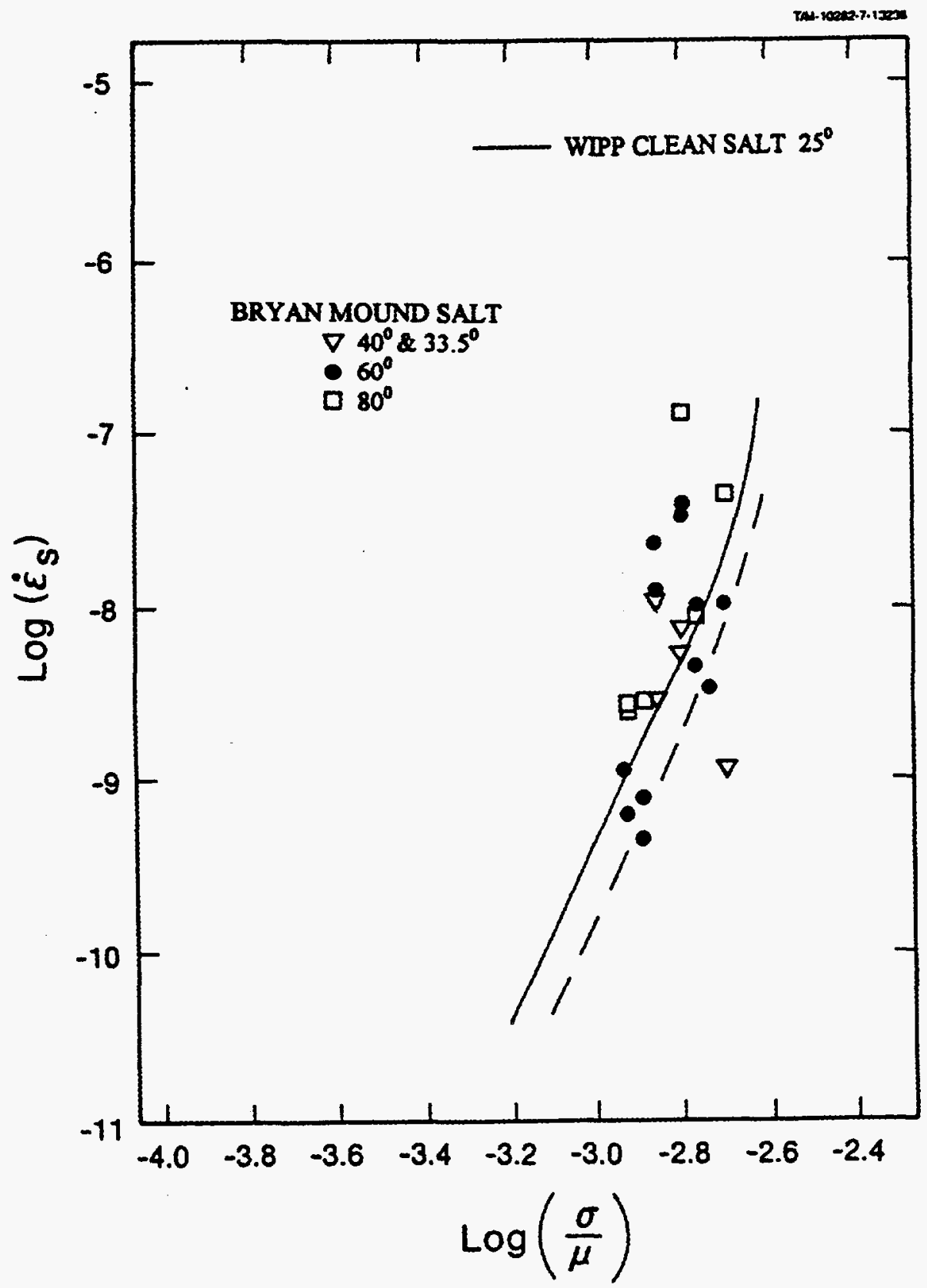

Figure 17. Incremental Test Creep Rates for Bryan Mound [Data of Wawersik and Zeuch, 1984]. 


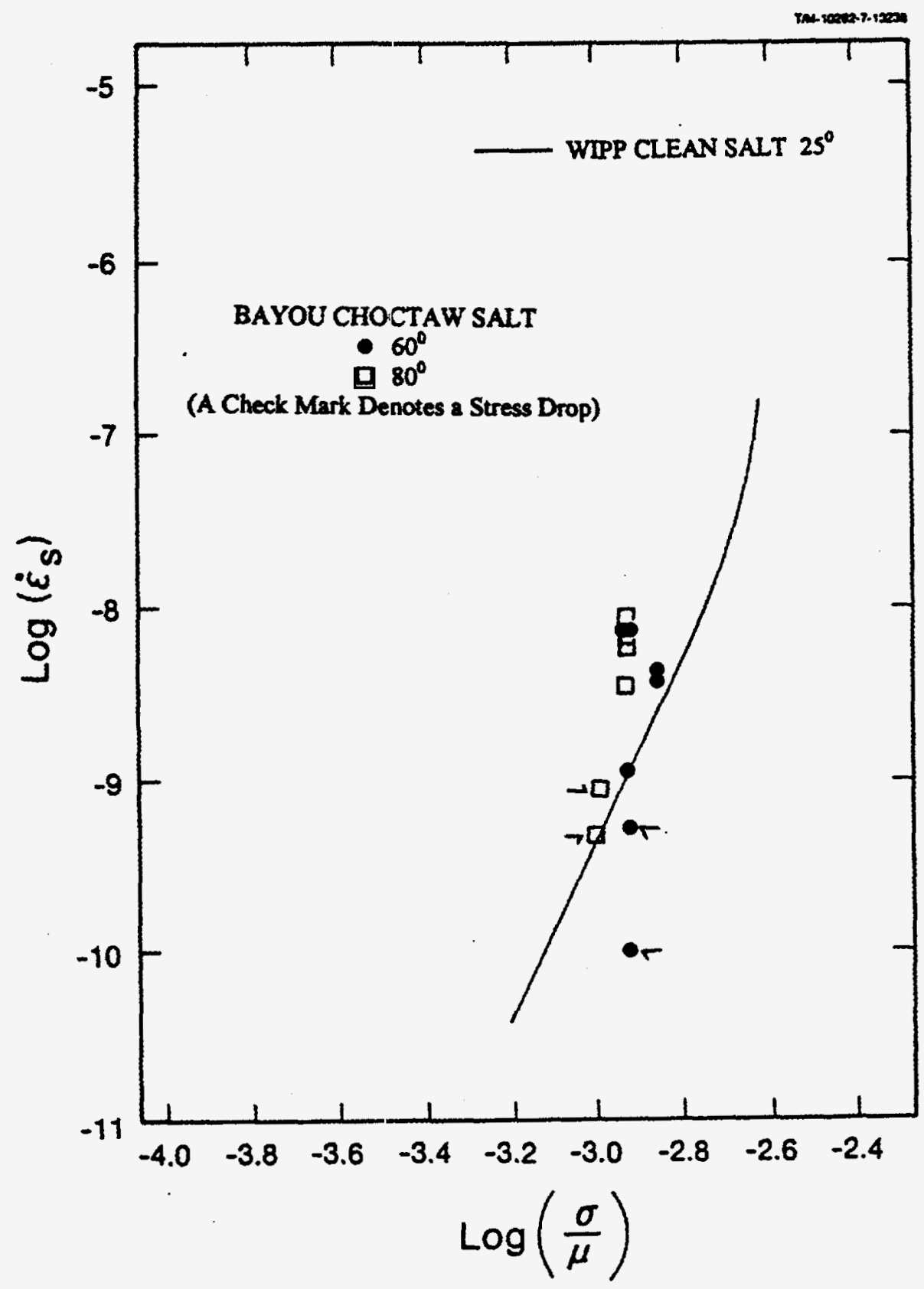

Figure 18. Incremental Test Creep Rates for Bayou Choctaw [Data of Wawersik and Zeuch, 1984]. 


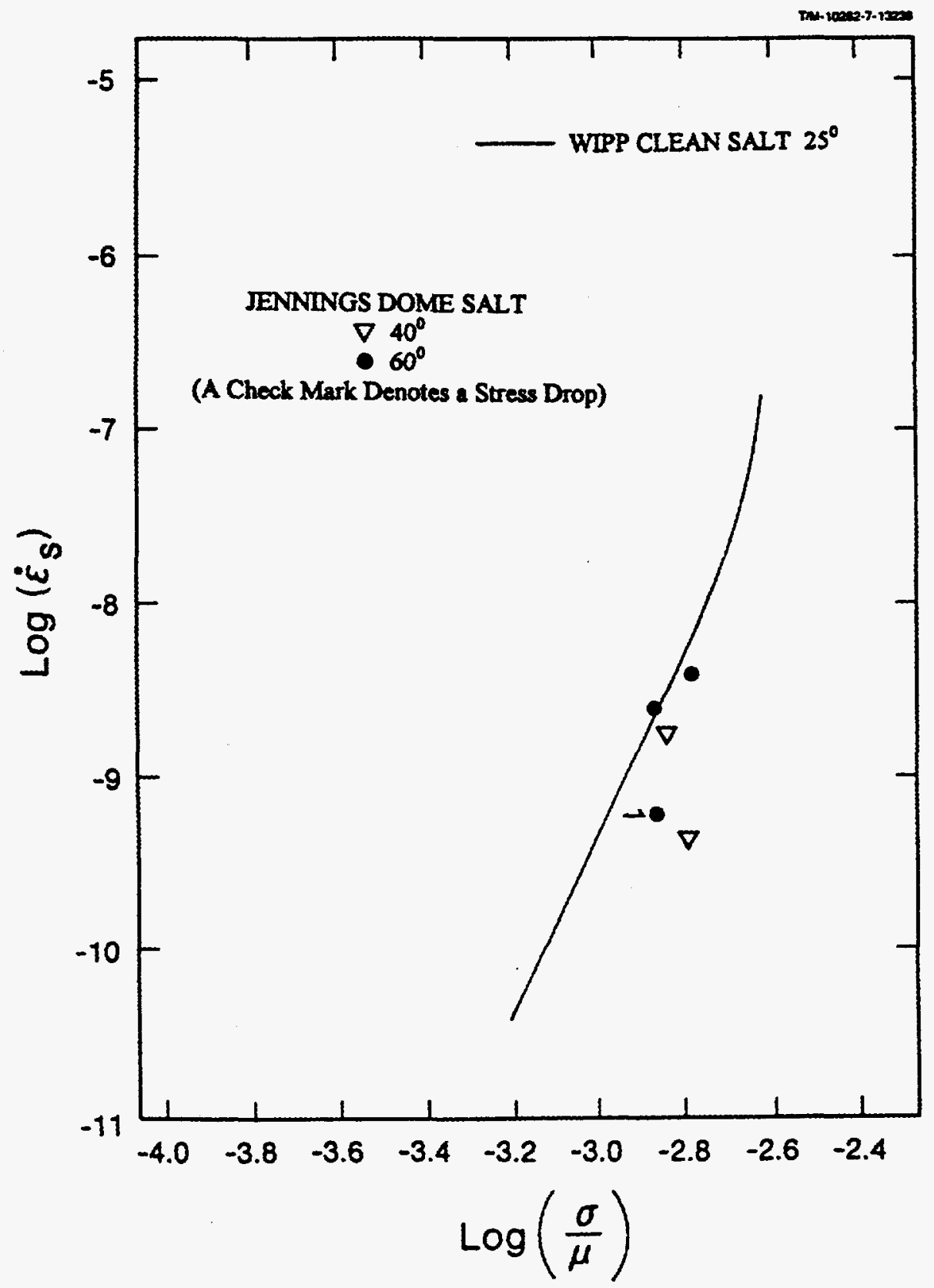

Figure 19. Incremental Test Creep Rates for Jennings Dome [Data of Wawersik and Zimmerer, 1994]. 


\subsection{BAYOU CHOCTAW (BC)}

Neal, et al. [1993b] analyzed the geology of the Bayou Choctaw dome and reported on some of the mineralogy. Core taken down to $728 \mathrm{~m}(2390 \mathrm{ft})$ from Well 101 was clear with 10 to 20 $\mathrm{mm}(0.4$ to $0.8 \mathrm{inch})$ diameter grains, and $1 \mathrm{~mm}(0.04 \mathrm{inch})$ gray anhydrite bands. Core from

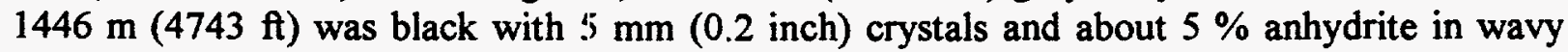
bands.

The creep response from one specimen of Bayou Choctaw salt prepared from core obtained from a deep borehole of Well 19A was determined using the incremental stress and temperature change procedure [Wawersik and Zeuch, 1984]. This material was medium grained, with the maximum grain size of $19 \mathrm{~mm}(0.75 \mathrm{inch})$ and with the principal impurity of uniformly distributed anhydrite crystals. The anhydrite concentration in this specimen probably was no more than $4.2 \%$, based on dissolution of specimen remains. The final increment rates as reported are shown in Figure 18. Unfortunately, the incremental tests involved several stress drops. If the stress drop increment results are eliminated (we do not show a plot of this), the $60^{\circ} \mathrm{C}$ minimum data are essentially identical to the $25^{\circ} \mathrm{C}$ WIPP clean salt baseline. The $80^{\circ} \mathrm{C}$ data are consistent, being offset somewhat above the $22^{\circ} \mathrm{C}$ Bayou Choctaw test results. As a consequence, the Bayou Choctaw material appears to be more creep resistant than the WIPP clean salt by about a factor of 0.17 , and consequently is very similar to the creep response of Bryan Mound.

\subsection{JENNINGS DOME (JD)}

A single specimen take from the deep borehole LA-1 at the Jennings dome was tested using the stress and temperature increment procedure [Wawersik and Zimmerer, 1994]. No information is available on specimen grain size or on impurity content. The increment final creep rates are plotted in Figure 19. The data involves only one stress drop, which we do not consider. The remaining $60^{\circ} \mathrm{C}$ Jennings Dome data agree well with $25^{\circ} \mathrm{C}$ WIPP clean salt baseline, which indicates the Jennings Dome salt has a greater creep resistance, again by about a factor of 0.17 . While the $40^{\circ} \mathrm{C}$ data fall below the $60^{\circ} \mathrm{C}$ data, as they must to be consistent, one data point exhibits an extremely low creep rate. 
(Page left intentionally blank) 


\subsection{DISCUSSION}

Our analysis of the creep of the dornal salts indicates that the well-defined creep tests on Avery Island and Weeks Island salt produce essentially the same behavior as the WIPP clean salt creep response. As a result, the M-D model appears to be an adequate description of domal salts. Extending this concept, the forms suggested by the model can be used to determine the possible steady state response envelope from the less well defined creep data of a number of materials from other salt domes. In addition to conventional creep tests, these materials were often tested using incremental stress and temperature change methods that require an analysis based on an understanding of transient creep response. Under certain circumstances, all these tests can lead to a definition of the steady state creep behavior. Because all of the creep tests were conducted at relatively low stress and low temperature, we can characterize the creep in terms of the structure factor of just one of the three mechanisms involved in salt creep. This is the undefined or empirical mechanism with the structure factor $A_{2}$. Values of the structure factor can be used to evaluate the relative creep "resistance" of the various domal salts compared to the WIPP clean salt creep baseline. In the discussion of individual creep data, the analysis of the domal salt creep data used temperature-corrected offsets to determine the most probable equivalent $25^{\circ} \mathrm{C}$-creep response. The $25^{\circ} \mathrm{C}$ equivalent offset amounts are summarized in Table IV. Here both the log 10 offset difference and the equivalent multiplication factor are given.

Table IV. Structure Factor Multiplication Factor from WIPP $25^{\circ} \mathrm{C}$ Pure Salt Baseline.

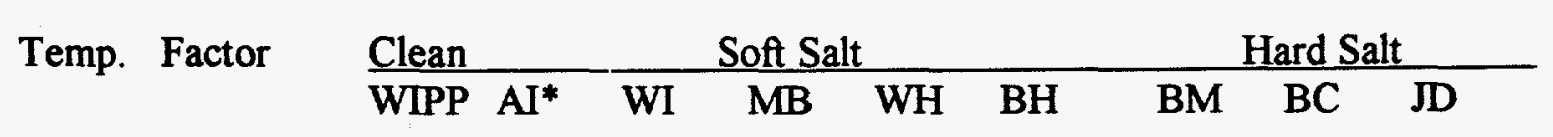

$\begin{array}{rllcccccccc}25^{\circ} \mathrm{C} & \text { Multiply by } & 1.0 & 0.71 & 0.59 & 1.0 & 1.23 & 1.29 & 0.17 & 0.17 & 0.17 \\ & \log _{10} \text { Differ. } & 0.00 & -0.14 & -0.23 & 0.00 & +0.09 & +0.11 & -0.76 & -0.77 & -0.77\end{array}$

* Because $A_{1}$ could be evaluated directly, this factor applies to $A_{2}$ only.

In discussing the results of our aralysis, one must remember that the database for any given salt material is very sparse and often further confused by experimental peculiarities. These facts leave considerable room for error in interpretation. As a result, no firm statements are currently possible, even though we: will deduce some possible conclusions. It appears from the table that not only is there some variation between the individual results, but also there are two relatively distinct groups of salt: responses. Four of the salts fall within the expected experimental uncertainty (about a factor of 2 , or $\log _{10}$ difference of $+/-0.30$ ) of the WIPP clean salt behavior. These salts are probably experimentally indistinguishable. However, three of the salts apparently fall beyond the uncertainty and form a distinct group of more creep resistant salts. 
Indirect substantiation of the effect of differences in the creep response of domal salt is found in the work of Ehgartner, et al. [1995] on loss of volume of petroleum storage caverns of the SPR. These results are produced from a CAVEMAN simulation methodology based on the MD creep equations. The methodology generates a set of "effective" fitting parameters for material, geometry, pressurization, and stress in the cavern setting as determined from cavern fluid loss histories and can be used to predict "effective" SPR cavern creep rates. These rates have been recently reported [Linn, 1997 ] from an ullage study. The effective creep rates in volume loss percentage per year (the same as a linear rate) are shown in Figure 20. Of the four facilities studied, Big Hill and West Hackberry show the highest creep volume loss rates; whereas, Bryan Mound and Bayou Choctaw show the lowest creep volume loss rates.

The reported volume creep rates certainly agree with the results suggested by Table IV. We would expect the cavern response to follow the laboratory creep responses. However, the volume loss results also suggest that the Bryan Mound dome must contain two different salt types, where Caverns BM 113, BM 114, BM115, and BM116 exhibit greater volume creep closure rates that are comparable to Big Hill and West Hackberry caverns.

Why some apparently high purity salts have greater creep resistance than other high purity salts is not known. Interestingly, the differences do not appear to form a continuous function with a gradation of behavior between the extremes. Rather, the effect seems discontinuous. Since most secondary strengthening agents, such as grain size, impurity contents, or second phase quantities lead to continuous changes, it is not satisfying to suggest simply that micromechanical agents lead to the observed behavior.

By applying ratios determined from the creep results, we can establish some suggested M-D creep parameters. However, the limited database permits only structure factors to be determined; all other parameters must be established on the basis of the WIPP clean salt database and the logical extension of the WIPP parameters, considering how material variation can affect the parameter. These results are given in Table V for WIPP clean salt, Weeks Island salt, the hard domal salts, and the soft domal salts. Those underlined quantities are extensions of WIPP parameter values based on theoretical values, micromechanical model parameter values, or atomistic models. The only parameter value that has no basis in the experimental data or a logical extension, and is therefore an assumed value, is the value of $\mathrm{K}_{0}$, which may indeed depend strongly upon specific salt material. These assumed values are in parentheses in the table. Unless more experimental information becomes available, $\mathrm{K}_{0}$ will be taken as either the WIPP clean salt value $\left(6.275 \times 10^{+5}\right)$, as given in Table V, or the WIPP argillaceous salt value $\left(1.783 \times 10^{+6}\right)$, depending upon the impurity content of the domal salt. When one suspects that a given domal salt is acting similar to argillaceous salt, it may also be necessary to reconstruct the table using the WIPP argillaceous parameters as a baseline material. Except for $\mathrm{K}_{0}$, the argillaceous creep parameters differ only slightly from the clean salt parameters. The argillaceous parameters are given elsewhere [Munson, 1997].

Another comparison of interest is to attempt a correlation between the creep properties and the propensity for caverns to produce salt falls. In a study of the cavern events leading to hanging string damage and failure, Munson, et al. [1998] suggested that many of these events could be attributed to salt falls. The speculation at that time was that the propensity for the formation of 
Table V. Suggested Parameter Values for the M-D Model.

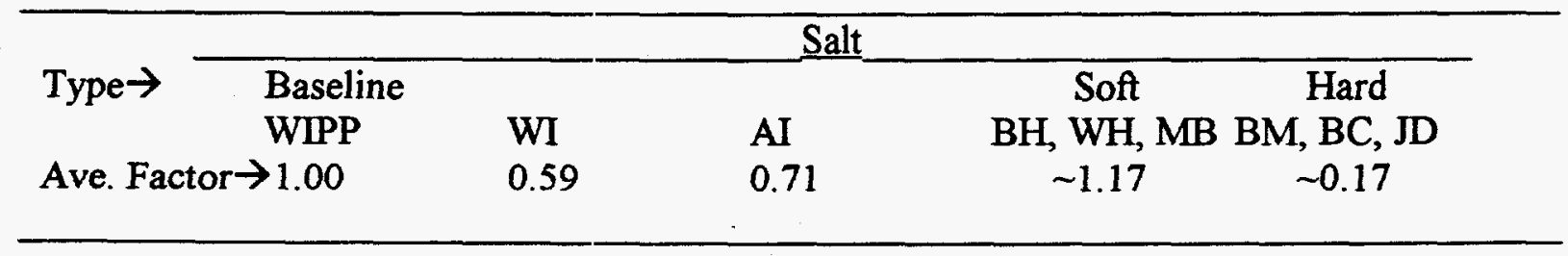

Parameter

$\begin{array}{lll}\mu & \mathrm{GPa} & \mathbf{1 2 . 4} \\ \mathrm{E} & \mathrm{GPa} & \mathbf{3 1 . 0} \\ \nu & & \mathbf{0 . 2 5}\end{array}$

\begin{tabular}{|c|c|c|c|c|c|}
\hline $\begin{array}{ll}\mathrm{A}_{1} & 1 / \mathrm{s} \\
\mathrm{Q}_{1} & (\mathrm{Cal} / \mathrm{mol})\end{array}$ & $\begin{array}{l}8.3865 \times 10^{+22} \\
25\end{array}$ & $\begin{array}{l}4.948 \times 10^{+22} \\
\underline{25}\end{array}$ & $\begin{array}{l}1.137 \times 10^{+22} \\
252525\end{array}$ & $9.812 \times 10^{+22}$ & $1.445 \times 10^{+22}$ \\
\hline$n_{1}$ & 5.5 & $\underline{5.5}$ & 5.5 & $\underline{5.5}$ & $\underline{5.5}$ \\
\hline$B_{1} 1 / s$ & $6.086 \times 10^{+6}$ & $\overline{5.417} \times 10^{+6}$ & $0.825 \times 10^{+6}$ & $7.121 \times 10^{+6}$ & $1.049 \times 10^{+6}$ \\
\hline$A_{2} 1 / s$ & $9.672 \times 10^{+12}$ & $5.706 \times 10^{+12}$ & $6.869 \times 10^{+12}$ & $11.32 \times 10^{+12}$ & $1.667 \times 10^{+12}$ \\
\hline $\mathrm{Q}_{2}(\mathrm{Cal} / \mathrm{mol})$ & 10 & $\underline{10}$ & 10 & $\underline{10}$ & $\underline{10}$ \\
\hline $\mathrm{n}_{2}$ & 5.0 & 5.0 & & 5.0 & 5.0 \\
\hline$B_{2} \quad 1 / s$ & $3.034 \times 10^{-2}$ & $2.700 \times 10^{-2}$ & $2.155 \mathrm{x}^{10-2}$ & $3.550 \times 10^{-2}$ & $0.523 \times 10^{-2}$ \\
\hline$\sigma_{0} \quad \mathrm{MPa}$ & $\begin{array}{l}20.57 \\
5.335 \times 10^{+3}\end{array}$ & $\begin{array}{l}20.57 \\
5.335 \times 10^{+3}\end{array}$ & $\begin{array}{l}20.57 \\
5.335 \times 10^{+3}\end{array}$ & $\begin{array}{l}20.57 \\
5.335 \times 10^{+3}\end{array}$ & $\begin{array}{l}20.57 \\
5.335 \times 10^{+3}\end{array}$ \\
\hline m & 3.0 & 3.0 & $\underline{3.0}$ & $\underline{3.0}$ & 3.0 \\
\hline $\mathrm{K}_{0}$ & $6.275 \times 10^{+5}$ & $\overline{6.275 \times 10^{+5}}$ & $1.342 \times 10^{+6}$ & $\left(6.275 \times 10^{+5}\right)$ & $\left(6.275 \times 10^{+5}\right)$ \\
\hline c & 0.009198 & 0.009198 & 0.009198 & 0.009198 & 0.009198 \\
\hline$\alpha$ & -17.37 & -17.37 & -13.20 & -17.37 & -17.37 \\
\hline$\beta$ & -7.738 & -7.738 & -7.738 & -7.738 & -7.738 \\
\hline$\delta$ & 0.58 & 0.58 & 0.58 & 0.58 & 0.58 \\
\hline$\omega$ & 0.0 & 0.0 & 0.0 & 0.0 & 0.0 \\
\hline
\end{tabular}

Bold numbers are determined from creep data for that specific salt dome material.

Underlined values are theoretical micromechanism constants and are the same as WIPP clean salt values.

$\mathrm{K}_{0}$ values in parentheses are assumptions.

All other values are assumed to be the same as the WIPP salt values or adjusted from the WIPP salt value in proportion to the $A_{2}$ value obtained experimentally for each individual domal salt, except for Avery Island salt where $A_{1}$ can be determined directly.

Because the Multimechanism Deformation (M-D) model is used, the equations given in this report require a zero value of $\omega$. 
salt falls was related to the material properties of the cavern salt. Indeed, it was suggested that the amount of impurities in the cavern salt governed the formation of salt falls, in accordance with the Multimechanism Deformation Coupled Fracture (MDCF) model [Chen, et al., 1992; 1996]. When we compare the events cavern by cavern, with the results in Figure 20 it is clear that most of the events occur in hard salt caverns; however, not all of them do. In Bryan Mound, a dome composed of two salt spines, with a soft salt spline, 41 of 45 events occur in what must be the predominantly hard salt caverns; the remaining four events are in caverns that possibly could be in soft salt. Bayou Choctaw, which is a dome of hard salt, has only one event. West Hackberry, a dome of soft salt, has experienced ten events, whereas, Big Hill, also a dome in soft salt, has experienced only one event. In summary, it appears that 42 events occurred in hard salt caverns and 15 events occurred in soft salt caverns. Clearly, there is only a weak, if any, correlation between the propensity for events or salt falls and the steady state creep behavior of the cavern salt. However, this lack of correlation could be a little misleading because the principal influence of impurities is not on the steady state rate but on the transient strain limit and fracture. Thus, impurity variations among the caverns might not be revealed by the differences in steady state creep rate. At this time, we do not have an accurate method to determine the impurity levels of these caverns. Any further statements would be speculation.

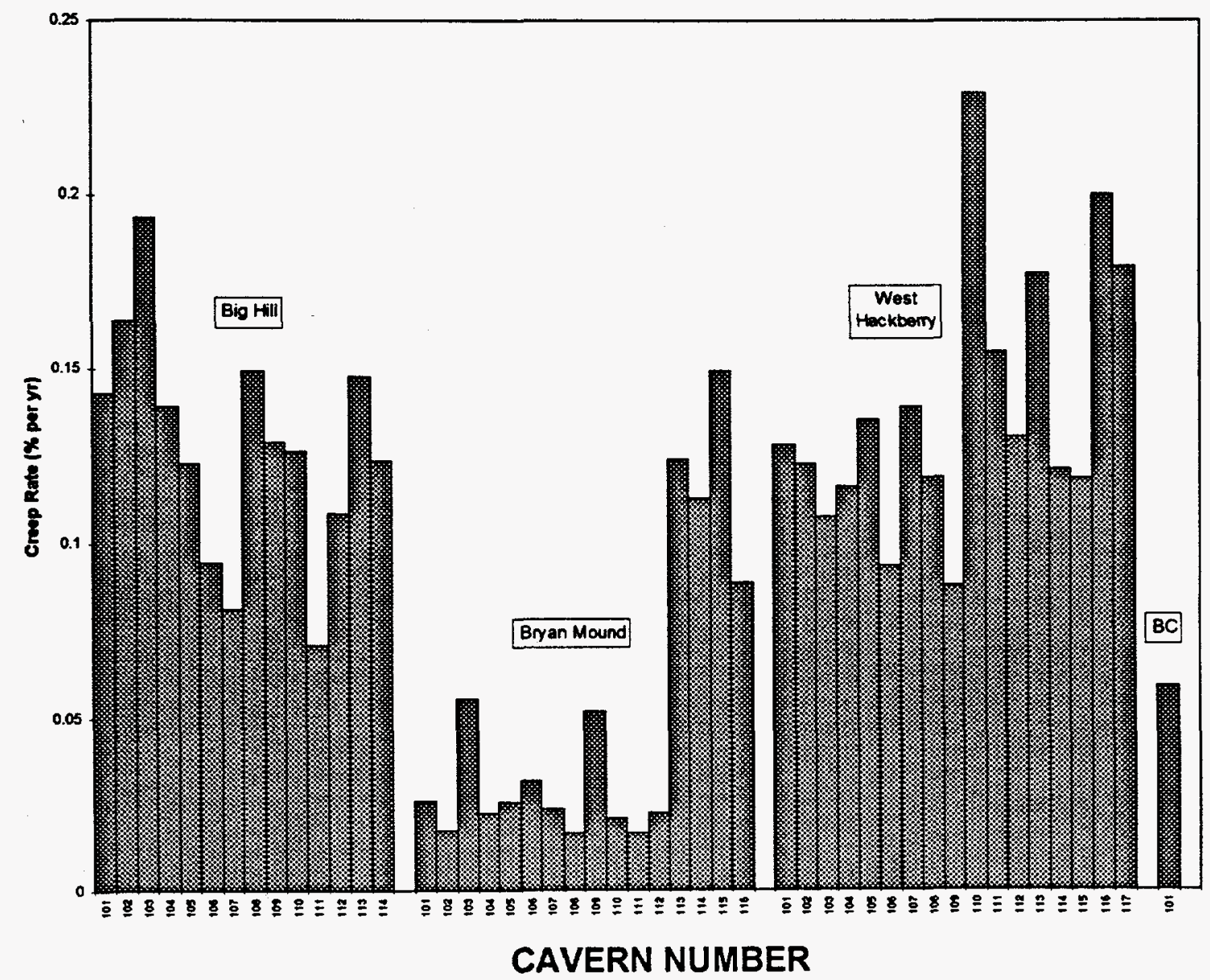

Figure 20. Caveman Calculated Volume Creep Rates for SPR Caverns [Linn, 1997]. 


\subsection{CONCLUSIONS}

The limited databases on salt creep from experimental studies of material from several salt domes, including the five SPR facility sites, have been analyzed using the procedures prescribed for the M-D model of salt creep. The M-D model was developed for the WIPP project. Even though the database information is limited, the parameter values for each domal salt have been established on the basis of the experimental data, theoretical values, material based extensions, or reasonable assumptions. Sufficient creep data are available from one SPR site (Weeks Island) and for Avery Island salt to indicate that they are consistent with the M-D model and the WIPP clean salt baseline. When all data are compared to the WIPP clean salt baseline response, there appear to be two types of materials: a creep resistant or hard salt and a soft salt with creep similar to the baseline material. The table of suggested M-D model parameters based on this analysis was generated and is available for potential future use.

Correlation of the steady state behavior to the propensity for hanging string damage from salt fall events in the SPR caverns, while significant, was not as marked as one might suppose. It is thought that the steady state creep behavior, as determined from this analysis, is less critical to determining salt fall potential than the more sensitive transient strain limit as influence by impurity content.

Perhaps the most significant result of the analysis is the potential for a limited number of creep tests on core obtained from potential cavern sites to give a good prediction of the cavern volume creep behavior. This has always been suspected to be the case, however, the potential is clearly demonstrated in this work and indicates the very interesting possible utilization of the available technology to anticipate cavern behavior prior to construction. 
(Page left intentionally blank) 


\section{REFERENCES}

Acres American, 1977. National Strategic Oil Storage Program, Weeks Island Mine Geotechnical Study, Report for Gulf Interstate Engineering Co., (Contract FEA-1251-75), Acres American, Inc., Buffalo, NY.

Acres American, 1979. Strategic Petroleum Reserve, Weeks Island Mine - Additional Geotechnical Studies, Report for Parsons-Gilbane (Contract 1-SC-5822-4013), Acres American, Inc., Buffalo, NY.

Chan, K.S., S.R. Bodner, A.F. Fossum, and D.E. Munson, 1992. A Constitutive Model for Inelastic Flow and Damage Evolution in Solids under Triaxial Compression, Mech. of Mat., $14,1-14$.

Chan, K.S., S.R. Bodner, D.E. Munson, and A.F. Fossum, 1996. Inelastic flow Behavior of Argillaceous Salt, Int'l. J. Damage Mech., 5, 292.

DeVries, K.L., 1988. Viscoplastic Laws for Avery Island Salt, Report for Stone Webster, RSI0333, RE/SPEC, Inc., Rapid City, S.D.

Ehgartner, B., S. Ballard, M. Tavares, S. Yeh, T. Hinkebein, and R. Ostensen, 1995. A Predictive Model for Pressurization of SPR Caverns, Fall Meeting Solution Mining Research Institute, October 23-24, San Antonio, TX

Ewing, R. I., 1981. Test of a Radiant Heater in the Avery Island Salt Mine, SAND81-1305, Sandia National Laboratories, Albuquerque, NM.

Kupfer, D.H., 1963. Structure of Salt in Gulf Coast Domes, $1^{\text {st }}$ Symp. on Salt, N. Ohio Geol. Soc. Cleveland, OH, pp. 104-123.

Linn, J.K., 1997. Memorandum to R.E. Myers, November 25, 1997 with attachment on "SPR Ullage Study" by B.L. Ehgartner, Sandia National Laboratories, Albuquerque, NM.

Magorian, T.R., and J.T. Neal, 1988. Strategic Petroleum Reserve (SPR) Additional Geologic Site Characterization Studies Big Hill Salt Dome, Texas, SAND88-2267, Sandia National Laboratories, Albuquerque, NM.

Magorian, T.R., J.T. Neal, S. Perkins, Q.J. Xiao, and K.O. Byrne, 1991. Strategic Petroleum Reserve (SPR) Additional Geologic Site Characterization Studies West Hackberry Salt Dome, Louisiana, SAND90-0224, Sandia National Laboratories, Albuquerque, NM.

Mellegard, K.D., 1983. Quasi-Static Strength and Creep Characteristics of 100-mm-Diameter Specimens of Salt from Avery Island, Louisiana, Technical Report ONWI-250, Office of Nuclear Waste Isolation, Battelle, Columbus, $\mathrm{OH}$. 
Mellegard, K.D., and T.W. Pfeifle, 1996. Laboratory Creep test on Domal Salt from Weeks Island, Louisiana, Topical Report RSI-0756, RE/SPEC Inc., Rapid City, SD.

Munson, D.E., 1979. Preliminary Deformation-Mechanism Map for Salt (with Application to WIPP), SAND70-0079, Sandia National Laboratories, Albuquerque, NM.

Munson, D.E., and P.R. Dawson, 1982. A Transient Creep Model for Salt during Stress Loading and Unloading, SAND82-0962, Sandia National Laboratories, Albuquerque, NM.

Munson, D.E., and P.R. Dawson, 1984. Salt Constitutive Modeling using Mechanism Maps, $1^{\text {st }}$ Int'1. Conference on the Mechanical Behavior of Salt, Trans Tech Publications, Clausthal, Germany, pp. 931-939.

Munson, D.E., A.F. Fossum, and P.E. Senseny, 1989. Advances in Resolution of Discrepancies between Predicted and Measured In Situ WIPP Room Closures, SAND88-2948, Sandia National Laboratories, Albuquerque, NM.

Munson, D.E., 1997. Constitutive Model of the Creep of Rock Salt Applied to Underground Room Closure, Int'1. J. Rock Mech. and Min. Sci. \& Geomech. Abstr., 34 (2), 233-248.

Munson, D.E., and B.L. Ehgartner, 1997. Memorandum to J.K. Linn, July 11, 1997. "Comparison of Steady State Creep Response of Weeks Island and WIPP Salt," Sandia National Laboratories, Albuquerque, NM.

Munson, D.E., M.A. Molecke, J.T. Neal, A.R. Sattler, and R.E. Myers, 1998 . Strategic Petroleum Reserve Caverns Casing Damage Update 1997, SAND98-0090, Sandia National Laboratories, Albuquerque, NM.

Neal, J.T., T.R. Magorian, R.L. Thoms, W.J. Autin, R.P. McCulloh S. Denzler, and K.O. Byrne, 1993a. Anomalous Zones in Gulf Coast Salt Domes with Special Reference to Big Hill, TX, and Weeks Island, LA, SAND92-2283, Sandia National Laboratories, Albuquerque, NM.

Neal, J.R., T.R. Magorian, K.O. Byrne, and S. Denzler, 1993b. Strategic Petroleum Reserve (SPR) Additional Geologic Site Characterization Studies Bayou Choctaw Salt Dome, Louisiana, SAND92-2284, Sandia National Laboratories, Albuquerque, NM.

Neal, J.R., T.R. Magorian, and S. Ahmad, 1994. Strategic Petroleum Reserve (SPR) Additional Geologic Site Characterization Studies Bryan Mound Salt Dome, Texas, SAND942331, Sandia National Laboratories, Albuquerque, NM.

Ortiz, T.S., 1980. Strategic Petroleum Reserve (SPR) Geological Summary Report Weeks Island Salt Dome, SAND80-1323, Sandia National Laboratories, Albuquerque, NM.

Senseny, P.E., 1983. Review of Constitutive Laws used to Describe the Creep of Salt, ONWI295, Office of Nuclear Waste Isolation, Battelle Memorial Institute, Columbus, OH. 
Senseny, P.E., 1983. Non-Associated Constitutive Laws for Low Porosity Rocks, Int'l J. Numerical and Analytical Methods in Geomechanics, 7, 101-115.

Senseny, P.E. 1986. Triaxial Compression Creep Tests on Salt from the Waste Isolation Pilot Plant, SAND85-7261, Sandia National Laboratories, Albuquerque, NM.

Senseny, P.E., 1989. Private communication, Re/Spec Inc., Rapid City, SD. Now published as a report: Senseny, P.E, 1990. Creep of Salt from the ERDA-9 Borehole and the WIPP Workings, SAND79-0076, Sandia National Laboratories, Albuquerque, NM).

Wawersik, W.R., D.J. Holcomb, D.W. Hannum, and H.S. Lauson, 1980a. Quasi-Static and Creep Data for Dome Salt from Bryan Mound, Texas, SAND80-1434, Sandia National Laboratories, Albuquerque, NM.

Wawersik, W.R., D.W. Hannum, and H.S. Lauson, 1980b. Compression and Extension Data for Dome Salt from West Hackbeny, Louisiana, SAND79-0688, Sandia National Laboratories, Albuquerque, NM.

Wawersik, W.R., and D.H. Zeuch, 1984. Creep and Creep Modeling of Three Domal Salts A Comprehensive Update, SAND84-0568, Sandia National Laboratories, Albuquerque, NM.

Wawersik, W.R., 1985. Memorandum to R.R. Beasley, January 3, 1985, "Creep Measurements on Big Hill Salt," Sandia National Laboratories, Albuquerque, NM.

Wawersik, W.R., 1992. Indicator Tests for the Creep of Rock Salt from Borehole Moss Bluff 2, Moss Bluff Dome, Texas, SANID92-2122, Sandia National Laboratories, Albuquerque, NM.

Wawersik, W.R., and D.J. Zimmerer, 1994. Triaxial Creep Measurements on Rock Salt from the Jennings Dome, Louisiana, Borehole LA-1, Core \#8, SAND94-1432, Sandia National Laboratories, Albuquerque, NM. 